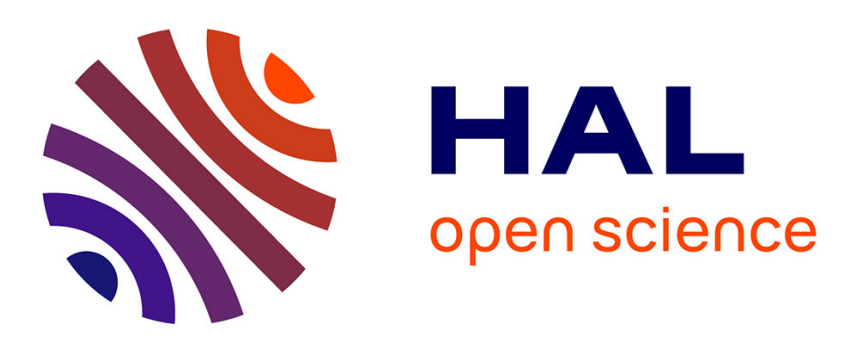

\title{
Mechanical characterization of a prototype a-C:Cr,Si and its tribological behavior at high temperature
}

\author{
Mariana Staia, Laurent Dubar, Mirentxu Dubar, Eli Saúl Puchi-Cabrera,
} Alain Iost, Patrick de Baets, André Dubois

\section{- To cite this version:}

Mariana Staia, Laurent Dubar, Mirentxu Dubar, Eli Saúl Puchi-Cabrera, Alain Iost, et al.. Mechanical characterization of a prototype a-C:Cr,Si and its tribological behavior at high temperature. Tribology International, 2016, 100, pp.242-254. 10.1016/j.triboint.2016.01.048 . hal-03169356

\section{HAL Id: hal-03169356 https://hal.science/hal-03169356}

Submitted on 16 Jun 2021

HAL is a multi-disciplinary open access archive for the deposit and dissemination of scientific research documents, whether they are published or not. The documents may come from teaching and research institutions in France or abroad, or from public or private research centers.
L'archive ouverte pluridisciplinaire HAL, est destinée au dépôt et à la diffusion de documents scientifiques de niveau recherche, publiés ou non, émanant des établissements d'enseignement et de recherche français ou étrangers, des laboratoires publics ou privés. 


\title{
Mechanical characterization of a prototype a-C:Cr,Si and its tribological behavior at high temperature
}

\author{
M.H. Staia ${ }^{\mathrm{a}, c, \mathrm{~d}, *, 1}$, L. Dubar $^{\mathrm{b}}$, M. Dubar ${ }^{\mathrm{b}}$, E.S. Puchi-Cabrera ${ }^{\mathrm{a}, \mathrm{b}, \mathrm{c}, 2}$, A. Iost $^{\mathrm{d}}$, P. de Baets ${ }^{\mathrm{e}}$, \\ A. Dubois ${ }^{\text {b }}$ \\ a Escuela de Ingeniería Metalúrgica y Ciencia de los Materiales, Facultad de Ingeniería, Universidad Central de Venezuela, \\ Los Chaguaramos, Caracas 1041, Venezuela \\ b Université Lille Nord de France, UVHC, LAMIH, UMR 8201, F-59313 Valenciennes, France

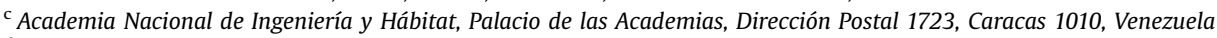 \\ ${ }^{\mathrm{d}}$ Arts et Métiers ParisTech, MSMP, Centre de Lille, 8, Boulevard Louis XIV, 59000 Lille Cedex, France \\ e Department of Mechanical Construction and Production, Ghent University, Technologiepark 903, Zwijnaarde, B-9052 Ghent, Belgium
}

\begin{abstract}
A B S T R A C T
The results of the mechanical and tribological characterization of a prototype a-C:Cr, Si sputtered coating are presented. The hardness and the elastic modulus of the coated system have been determined by means of nanoindentation taking into account the actual architecture of the bi-layer coating. Both mechanical properties were recorded continuously versus the indentation depth, $h$, up to approximately $2000 \mathrm{~nm}$, at a constant indentation rate and maximum applied loads of $700 \mathrm{mN}$. The results were analyzed by means of the Oliver and Pharr method and modeled on the basis of novel approach proposed recently by some of the authors. Wear tests were conducted at $25^{\circ} \mathrm{C}, 400{ }^{\circ} \mathrm{C}$ and $450{ }^{\circ} \mathrm{C}$ against alumina, employing a contact pressure of $540 \mathrm{MPa}$. Characterization of the worn surfaces by SEM and elemental Xray mapping has also been carried out. A wear rate as low as $1.2 \times 10^{-18} \mathrm{~m}^{3} / \mathrm{N}$ m was determined for the coating tested at $25^{\circ} \mathrm{C}$, which is approximately one order of magnitude and three times less than those found from the tests performed at $400{ }^{\circ} \mathrm{C}$ and $450{ }^{\circ} \mathrm{C}$, respectively. It has been determined that the a-C: $\mathrm{Cr}$,Si coating exhibits a very good wear resistance even at temperatures up to $450{ }^{\circ} \mathrm{C}$, as consequence of the $\mathrm{Si}$ and $\mathrm{Cr}$ oxides formed due to the oxidation process. Also, it has found that at this temperature, a continuous oxide film is formed, which reduces the wear rate of the coated system in comparison to that determined at $400{ }^{\circ} \mathrm{C}$. However, the volume increase due to the oxidation process at $450{ }^{\circ} \mathrm{C}$ and the elimination of $\mathrm{CO}_{2}, \mathrm{Ar}$ and $\mathrm{H}_{2} \mathrm{O}$ vapors, induces a severe surface cracking of the coating.
\end{abstract}

\section{Introduction}

The use of DLC at high temperatures has always constituted a challenge for the scientific community, as a need to fulfill the requirements of different industries. As an example, in sheet metal forming processes, DLC coatings can act as solid lubricants to enable dry or nearly dry processes [1-3], whereas for the extrusion and machining processes of aluminum alloys, these can also be employed due to their anti-sticking properties [4].

Although, carbon-based a-C and a-C:H films belong to the DLC coatings family, their performance is totally different taking into account both the amount of $\mathrm{H}$ concentration and method of deposition, which will influence considerably their mechanical properties, as indicated by Bull in an earlier work [5].

Nevertheless, the key properties and differences among the main groups have been thoroughly described by Neuville and Matthews [6], whereas the history of their development, as well as the transference from experiments to industrial applications have been recently presented by Bewilogua and Hofmann [7]. These authors have also indicated the effect of the change in the composition of DLC coatings, as consequence of the incorporation of metals and/or non-metals, in order to improve their adhesion, mechanical properties and/or thermal stability. 
Various studies were carried out in the last two decades in order to test the tribological response of a-C and a-C:H coatings. An important part of these studies, related to magnetron sputtered coatings, were conducted with the aim of implementing their application in the cutting and metal forming processing of aluminum alloys, both at low and high temperatures [8-10]. Konca et al. [9] studied the friction and wear behavior of nonhydrogenated DLC coatings at elevated temperature against a 319 Al alloy, tungsten carbide (WC) and sapphire balls. The coatings (two DLC obtained at 60 and $80 \mathrm{~V}$, respectively) were produced by unbalanced magnetron sputtering ion plating using Teer Coating deposition systems (Worcestershire, UK). These coatings have $\mathrm{Cr}$ in their composition, whose content decreases with distance from the interface. The authors determined that during the wear tests, the wear resistance starting even at a temperature as low as $120^{\circ} \mathrm{C}$ was poor, as compared to those conducted at room temperature and that the $\mathrm{Al}$ alloy ball caused a more severe damage than the other two counterparts employed.

An interesting comparison between hydrogenated and nonhydrogenated DLC coatings produced by unbalanced magnetron sputtering at Teer Coatings, UK was performed by $\mathrm{Ni}$ and coworkers [10], who studied their friction, wear and adherence propensity at $25^{\circ} \mathrm{C}$ and $240{ }^{\circ} \mathrm{C}$, by sliding them against 319 aluminum pins. Both kinds of DLC coatings, which have a common architecture, i.e. a $\mathrm{Cr}$ film and $\mathrm{CrC}$ transition layer built before depositing the DLC, performed well at room temperature. However, at elevated temperature, aluminum adhered to the nonhydrogenated DLC coating, whereas the hydrogenated DLC maintained its non-sticking nature, but with an impaired wear resistance. Gharam et al. [11] made an important contribution on this subject and showed that the incorporation of $\mathrm{W}$ in the DLC coatings during deposition could give rise to different tribological responses, as a function of the temperature interval during wear testing against $319 \mathrm{Al}$ alloy pins. The best results obtained, in which the coatings did not fail, were reported at $400{ }^{\circ} \mathrm{C}$ and $500{ }^{\circ} \mathrm{C}$. This behavior was attributed to the formation of a tungsten oxide layer on the coating surface and the transfer of this layer to the Al counterface. Zou et al. [12] deposited DLC coatings doped with a different $\mathrm{Cr}$ content by employing a combined system consisting of a middle frequency (MF) magnetron sputtering and ion plating. These researchers reported a good tribological behavior at $400{ }^{\circ} \mathrm{C}$ for $4.8 \% \mathrm{Cr}$-DLC doped coating against an $\mathrm{A} 319 \mathrm{Al}$ sliding counterface.

Other investigations reported in the literature were dedicated to studying the influence of doping elements on the thermal stability of DLC sputtered coatings [12,13]. Zhang et al. [13] embedded nanocrystalline $\mathrm{TiC}$ into the a-C matrix doped with $\mathrm{Al}$ to form nc$\mathrm{TiC} / \mathrm{a}-\mathrm{C}(\mathrm{Al})$ nanocomposite film amorphous carbon (a-C). These authors reported a good thermal stability of the coating up to $600{ }^{\circ} \mathrm{C}$, without observing any coating thickness decrease or change in hardness with temperature. Hofmann et al. [14], by employing magnetron based deposition processes under industrial coating conditions with intensive ion bombardment, produced a new Si-DLC (a-C:H:Si) based coatings with $5 \% \mathrm{H}$ content and a silicon concentration of both 9 and 19 at\% Si. Under dry conditions, these coatings exhibited friction coefficients with only the half of the value of that corresponding to a pure a-C:H coating and a better thermal stability up to $500{ }^{\circ} \mathrm{C}$, although the abrasive wear rate, determined by the crater method, increased as the Si content raised. The review of these articles shows a clear evolution in time of the sputtered coatings composition in order to fulfill the required performance.

Recently, some interesting results have been published in relation to a-C coatings doped with small amounts of either $\mathrm{Si}$ or $\mathrm{Cr}$, in order to achieve a better thermal stability. The deposition was carried out by means of a Teer UDP -650 closed field unbalanced magnetron sputtering device [15]. Similar deposition conditions were applied to obtain an a-C, a-C:Cr and an a-C:Si coating of similar thickness, with the aim of comparing their tribological behavior at high temperature, up to $450{ }^{\circ} \mathrm{C}$. The $\mathrm{Cr}$ content of these coatings varied between $0.5-10 \% \mathrm{Cr}$ and the Si content between $0.1-5 \%$, depending on the applied target current, as reported [16]. It was determined that a considerable improvement related to the thermal stability of the a-C:Si coatings, as compared to the other two, took place. Their performance was attributed to the possible Si compound formed during wear testing at a temperature of $325^{\circ} \mathrm{C}$.

Thus, the present work has been carried out in order characterize the mechanical properties by nanoindentation and investigate the high temperature wear behavior of a new prototype a-C coating doped with both $\mathrm{Cr}$ and $\mathrm{Si}$ in small quantities (a$\mathrm{C}: \mathrm{Cr}, \mathrm{Si}$ ), which was deposited on a M42 steel substrate, employing for this purpose a number of different experimental techniques.

\section{Experimental}

The coating used in the present investigation is a prototype amorphous carbon non-hydrogenated, mostly $\mathrm{sp}^{2}$ bonded, of approximately $2.3 \pm 0.1 \mu \mathrm{m}$ in thickness and $\mathrm{Ra}=0.01 \mu \mathrm{m}$. The coating was developed at MIBA-Teer Coatings (Worcestershire, UK) and deposited in a Teer UDP - 650 closed field unbalanced magnetron sputtering reactor. The deposition parameters were similar of those reported elsewhere [15]. After an ion cleaning process, the M42 tool steel was coated with a thin $0.2 \mu \mathrm{m}$ chromium buffer layer, which converges gradually into the amorphous-carbon hard coating doped with small quantities of $\mathrm{Si}$ and $\mathrm{Cr}(\mathrm{a}-\mathrm{C}: \mathrm{Cr}, \mathrm{Si})$ coating [16]. This deposition process produces a $\mathrm{Cr}$ thin layer followed by a graded $\mathrm{CrCSi}$ layer and finally an a-C doped coating, with a small and constant \% of $\mathrm{Cr}$ and Si. The whole coating is of approximately $2.3 \mu \mathrm{m}$ in thickness and, as far as the modeling of the changes in hardness and elastic modulus with penetration depth is concerned, it will be considered in the forthcoming that the coating is composed of two layers: a $\mathrm{CrCSi}$ graded layer of approximately $0.2 \mu \mathrm{m}$ and an a-C doped coating of approximately $2.1 \mu \mathrm{m}$. The design of such interface was proposed by Bohme et al. [17], where the combination of a $\mathrm{Cr}$ buffer layer, a $\mathrm{CrC}$ gradient layer and an $\mathrm{a}-\mathrm{C}$ hard coating layer were able to ensure a sound coating adherence to the HSS steel substrate

Given the fact that the behavior of the coated system under indentation loading is representative of the energy dissipation processes associated with contact damage [18], it is important to provide a detailed analysis of the changes in hardness and elastic modulus of the coated system with penetration depth.

The hardness and the elastic modulus of the coated system have been determined by means of nanoindentation tests using a MTS XP Nano Indenter equipped with a Berkovich indenter. The apparatus was operated under a continuous stiffness measurement mode. Prior to indentation, the tip calibration was carried out on fused silica. The calibration curves for the fused silica standard have been reported elsewhere [19]. A total of 20 indentations were conducted over the three different samples tested for this purpose and the elastic modulus, $E$, and hardness, $H$, were recorded continuously versus the indentation depth, $h$, up to approximately $2000 \mathrm{~nm}$, at a constant indentation rate of $0.05 \mathrm{~s}^{-1}$ and maximum applied loads of $700 \mathrm{mN}$. The results were analyzed by means of the Oliver and Pharr method [20].

The adhesive strength of the coating was tested by using a commercial scratch tester Millenium (Tribotechnic) fitted with a Rockwell spherical diamond indenter (tip radius of $200 \mathrm{~mm}$ ). Scratch tests were conducted using progressive loads from 1 to $60 \mathrm{~N}$ for a scratch length of $5 \mathrm{~mm}$. A load rate of $120 \mathrm{~N} \mathrm{~min}^{-1}$ and 
a constant sliding speed of $10.0 \mathrm{~mm} \mathrm{~min}^{-1}$ were employed. The scratch tester is equipped with an acoustic emission and frictional force monitoring sensors.

Sliding wear tests were conducted according to the ASTM G 99-95a standard, for assessing the influence of temperature on the friction and wear behavior of the coating. A ball-on-disc configuration on a high-temperature tribometer (CSM, Switzerland) was used. The tests were carried out under atmospheric unlubricated conditions with $40 \pm 5 \%$ relative humidity. Commercial available alumina balls with a diameter of $10 \mathrm{~mm}$ were employed as static counterpart. Before each wear test, both the ball and disc specimens were cleaned ultrasonically in distilled water with a detergent solution ( $2 \%$ Tickopur R33, $50{ }^{\circ} \mathrm{C}, 15 \mathrm{~min}$ ) and immersed in acetone. Subsequently, the samples were cleansed in cold distilled water and dried in a stream of air. The coefficient of friction was obtained from the ratio of the measured friction force and the applied normal force on the surface.

Basically, the wear experiments were carried out by triplicate at room temperature (RT), $400^{\circ} \mathrm{C}$ and $450{ }^{\circ} \mathrm{C}$, respectively. The heating of the coated samples was done in the tribometer by controlling their temperature. When the temperature of the specimen achieved the desired test temperature, the alumina ball was put in contact with the sample. The normal load applied during the test was of $1 \mathrm{~N}$. This value was chosen in order to obtain a contact pressure of few hundreds of MPa, similar to those found in aluminum extrusion dies during operation and temperature close to the temperatures achieved in the extrusion dies of aluminum alloy [21-23]. All the tests, irrespective of the temperature, were conducted using 2100 laps (60 m sliding distance), $0.1 \mathrm{~m} / \mathrm{s}$ sliding velocity using a $4.5 \mathrm{~mm}$ rotating radius. It is important to point out that the sliding distance employed in the present work was chosen on the basis of previous investigations carried out employing different DLC coated systems $[8,9,11,15]$.

The morphological characterization of the surface conditions of the samples under study before and after wear testing was conducted by using a scanning electron microscope (SEM, XL - 30 FEG, FEI, Philips, Eindhoven, The Netherlands), equipped with an energy disperse X-ray spectrometer (EDAX-Dx-4i, Philips, Eindhoven, The Netherlands). Element X-ray mapping was also carried out in order to determine the element distribution in the wear scar at the corresponding test temperature. A Veeco Wyko NT9300 profilometer was used for roughness and wear track measurements.

The specific wear rate, $k$, was computed from the ratio between wear volume and the applied load per unit of sliding distance $\left(\mathrm{m}^{3} / \mathrm{N} \mathrm{m}\right)$. The wear volume was obtained by multiplying the cross-sectional wear track area by the length of the wear track. In order to determine the mean cross-sectional track area, eight individual wear profiles were fitted by means of a spline function with cubic ends and interpolated at each experimental depth data point. Each individual area was subsequently determined by integrating numerically the interpolated function between the initial and final experimental depth data points. The cross-sectional area was computed as the mean of these eight individual curves. The coatings wear rate was expressed as the worn volume divided by the product of normal load and the number of laps.

\section{Results and discussion}

\subsection{Coating hardness}

Fig. 1 illustrates the change in hardness with indentation depth for the coated system under investigation. The experimental data include approximately six thousand data points, distributed in a

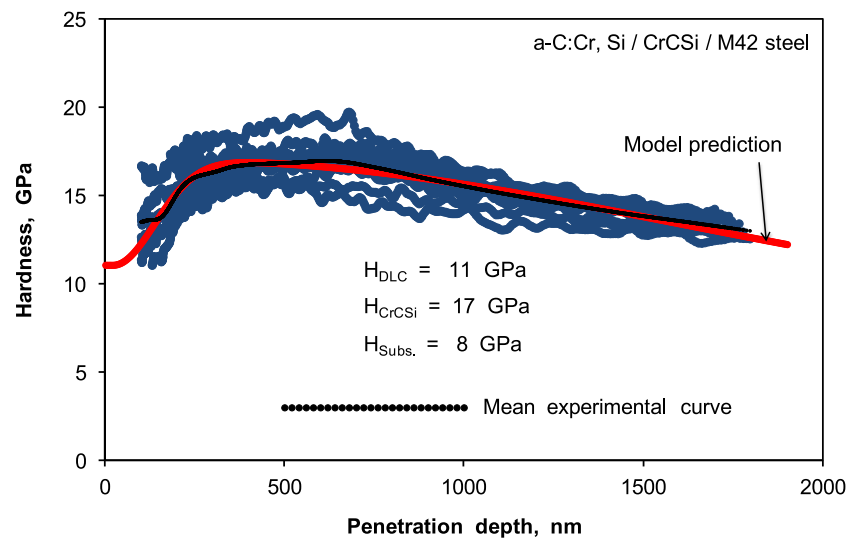

Fig. 1. Change in hardness with penetration depth for the a-C:Cr, Si/CrCSi/M42 steel coated system, considering its bilayer architecture. The data have been described with the model advanced by Puchi-Cabrera $[25,26]$, modified for multilayer coatings [19]. The hardness values computed for the individual layers, as well as the substrate hardness are given on the plot.

wide scatter band. The hardness is observed to increase from approximately $11 \mathrm{GPa}$ at indentation depths of about $100 \mathrm{~nm}$, to approximately $20 \mathrm{GPa}$ at about $680 \mathrm{~nm}$. After such a transient, the hardness decreases steadily to the value corresponding to that of the steel substrate, of approximately $8 \mathrm{GPa}$.

The hardness value of the fused silica standard employed in the calibration of the Berkovich indenter used in the present investigation is of approximately $12 \mathrm{GPa}$. During the calibration procedure, such a hardness value could only be reproduced for indentation depths above approximately $100 \mathrm{~nm}$. Therefore, in the present work, it has been considered that for indentation depths greater than this value, the plastic zone below the indenter tip is fully developed which, as pointed out by Chen and Bull [24] constitutes a fundamental condition that should be fulfilled for validating the hardness measurement.

On the basis of the mean experimental curves shown in Figs. 1 and 3, it has been determined that the ratio of $\mathrm{H} / \mathrm{E}$ for this coated system decreases steadily from approximately 0.085 at $100 \mathrm{~nm}$ to about 0.009 at $5700 \mathrm{~nm}$. Therefore, according to the equation proposed by Chen and Bull [24], the ratio of the plastic zone radius underneath the indenter to the plastic indentation depth, $R_{\mathrm{p}} / \delta_{\mathrm{m}}$, will increase from approximately 3.45-4.42 in the same indentation depth.

Consequently, on the basis of the calibration procedure, it has been assumed that, also in the bi-layer coating, for indentation depths greater than approximately $100 \mathrm{~nm}$, the plastic zone under the indenter tip is fully developed and that the hardness measurements are validated, which allows the use of such a data in the analysis. Therefore, the complex behavior exhibited in Fig. 1 could be explained in terms of the sequential contribution to the composite hardness of the different materials, which encompass the coated system.

Thus, the hardness versus penetration depth curve for this bilayer coating can be readily analyzed following the methodology recently advanced by Puchi-Cabrera et al. [19], which allows the extension of any hardness model employed for the description of the composite hardness of systems involving monolayer coatings, to the analysis of multilayer coatings under indentation loading. Accordingly, the extension of the model proposed by PuchiCabrera $[25,26]$ for the analysis of this bi-layer coating can be computationally instrumented in the following manner. Firstly, for each value of the indentation depth, $h$, the volume fraction of the doped DLC coating, $a_{\mathrm{f}}{ }^{\text {(DLC) }}$, which contributes to the composite 
hardness is calculated as follows:

$a_{\mathrm{f}}{ }^{(\mathrm{DLC})}=1$ if $\quad h<K_{\mathrm{f}}{ }^{(\mathrm{DLC})} t_{\mathrm{f}}{ }^{(\mathrm{DLC})}$

Otherwise :

$\left.a_{\mathrm{f}}^{(\mathrm{DLC})}=\exp \left[-\frac{h-K_{\mathrm{f}}^{(\mathrm{DLC})} t_{\mathrm{f}}{ }^{(\mathrm{DLC})}}{\beta_{\mathrm{p}}{ }^{(\mathrm{DLC})} t_{\mathrm{f}}{ }^{(\mathrm{DLC})}}\right)^{2}\right]$

In the above equation, $\mathrm{K}_{\mathrm{f}}^{\mathrm{DLC}}$ represents the coating thickness fraction above which the $\mathrm{CrCSi}$ layer located underneath starts to contribute to the composite hardness, $t_{\mathrm{f}}{ }^{\text {(DLC) }}$ the DLC coating thickness and $\beta_{\mathrm{p}}{ }^{\text {(DLC) }}$ a material constant.

Secondly, the computation of the volume fraction of CrCSi layer, which contributes to the composite hardness, is given by:

$a_{\mathrm{f}}{ }^{(\mathrm{CrCSi})}=1-a_{\mathrm{f}}{ }^{(\mathrm{DLC})}$ if $h<K_{\mathrm{f}}{ }^{(\mathrm{DLC})} t_{\mathrm{f}}{ }^{(\mathrm{DLC})}+K_{\mathrm{f}}{ }^{(\mathrm{CrCSi})} t_{\mathrm{f}}{ }^{(\mathrm{CrCSi})}$

Otherwise :

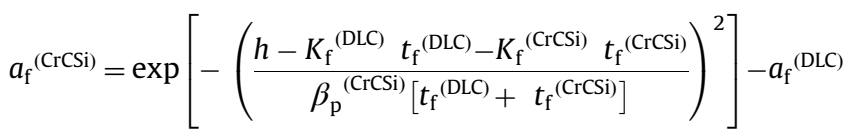

Finally, the volume fraction of the M42 steel substrate is computed as:

$a_{\mathrm{f}}^{(\text {Subst. })}=1-a_{\mathrm{f}}^{(\mathrm{DLC})}-a_{\mathrm{f}}^{(\mathrm{CrCSi})}$

Therefore, for each value of $h$, the predicted composite hardness can be expressed as a linear law of mixtures:

$\mathrm{H}=a_{\mathrm{f}}^{\text {(DLC) }} H_{\mathrm{DLC}}+a_{\mathrm{f}}^{\text {(CrCSi) }} H_{\mathrm{CrCSi}}+a_{\mathrm{f}}^{\text {(Subst.) }} H_{\text {Subst. }}$

Table 1 summarizes all the values of the different constants involved in the formulation presented in Eqs. (1) through (4).

Fig. 1 also illustrates the prediction of the model, which is observed to be quite satisfactory and to agree very well with the mean experimental curve. Accordingly, the doped DLC coating exhibits a hardness of $11 \mathrm{GPa}$, whereas the $\mathrm{CrCSi}$ layer has a hardness of $17 \mathrm{GPa}$. Similar results are obtained with the extended models proposed by Jönsson and Hogmark [27] and Korsunsky et al. [28]. Thus, according to the model, up to indentation depths of approximately $20 \mathrm{~nm}$ the composite hardness is entirely determined by the DLC coating. However, due to fracture of the latter under indentation loading, for h values greater than $20 \mathrm{~nm}$, the composite hardness will be determined both by the DLC and CrCSi films. A significant contribution of the substrate to the composite hardness will only take place for indentation depths above $400 \mathrm{~nm}$.

If the coating is incorrectly assumed to be a monolayer film, its hardness can be easily determined on the basis of the ISO14577-4 standard [29]. For this purpose and according to the mean experimental curve shown in Fig. 1, all the experimental data corresponding to an indentation depth of less than approximately $500 \mathrm{~nm}$ should be disregarded and the coating hardness could be

Table 1

Constants involved in the Puchi-Cabrera model for the bi-layer doped DLC and CrCSi film deposited onto a M42 steel substrate.

\begin{tabular}{ll}
\hline$H^{(\mathrm{DLC})}$ & $11 \mathrm{GPa}$ \\
$K^{(\mathrm{DLC})}$ & 0.01 \\
$\beta_{\mathrm{P}}{ }^{(\mathrm{DLC})}$ & 0.078 \\
$H^{(\mathrm{CrCSi})}$ & $17 \mathrm{GPa}$ \\
$K^{(\mathrm{CrCSi})}$ & 1 \\
$\beta_{\mathrm{P}}{ }^{(\mathrm{CrCS} i)}$ & 0.843 \\
$H_{\text {Subst. }}$ & $8 \mathrm{GPa}$ \\
\hline
\end{tabular}

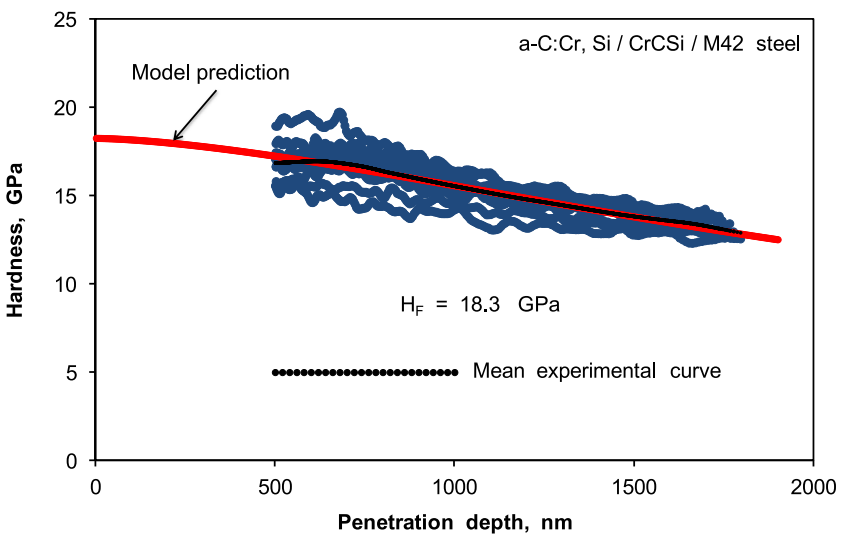

Fig. 2. Change in hardness with penetration depth for the a-C:Cr, $\mathrm{Si} / \mathrm{CrCSi} / \mathrm{M} 42$ steel coated system, assuming that the coating is a monolayer film. The data have been described with the model advanced by Puchi-Cabrera for monolayer coatings $[25,26]$. The hardness values computed both for the film and substrate are given on the plot.

Table 2

Constants involved in the Puchi-Cabrera model assuming a monolayer film deposited onto the M42 steel substrate.

\begin{tabular}{ll}
\hline$H_{\mathrm{F}}$ & $18.3 \mathrm{GPa}$ \\
$\beta_{\mathrm{P}}$ & 0.94 \\
$n_{\mathrm{P}}$ & 1.55 \\
$H_{\text {Subst. }}$ & $8 \mathrm{GPa}$ \\
\hline
\end{tabular}

determined either as the maximum constant value corresponding to the mean curve or by extrapolation of the composite hardness to $h=0$, by means of any of the existing models.

The mean experimental curve shown in Fig. 1 indicates that a plateau is attained at an indentation depth of approximately $500 \mathrm{~nm}$, at which the hardness of the coating is found to be about $17 \mathrm{GPa}$. Such a hardness value would represent the actual coating hardness according to the ISO14577 - 4 standard [29]. However, in order to avoid any influence of the substrate in the determination of the absolute hardness of the coating, extrapolation to $h=0$ could be carried out by means of any of the models available for this purpose.

Fig. 2 illustrates this procedure, in which the coating hardness has been determined employing the model advanced by PuchiCabrera $[25,26]$, according to which the composite hardness, $H_{\mathrm{C}}$, is expressed as:

$H_{\mathrm{C}}=H_{\text {Subst. }}+\left(H_{\mathrm{F}}-H_{\text {Subst. }}\right) \exp \left[-\left(\frac{h}{\beta_{\mathrm{p}} t_{\mathrm{F}}}\right)^{n_{\mathrm{p}}}\right]$

Table 2 summarizes the value of all constants involved in this case.

Accordingly, the coating exhibits a hardness of approximately 18.3 GPa, which is very close to the value obtained from the ISO14577 - 4 standard, as well as the values reported by Jantschner et al. [15] for a-C and a-C:Si films, of approximately 16.5 and 16.9 GPa, respectively.

However, the clear disadvantage of this method for finding out the global coating hardness is that it does not allow the determination of either the hardness value of the different layers, which encompass the coated system, or the sequence in which each layer contributes to the composite hardness as the indentation loading is applied. 


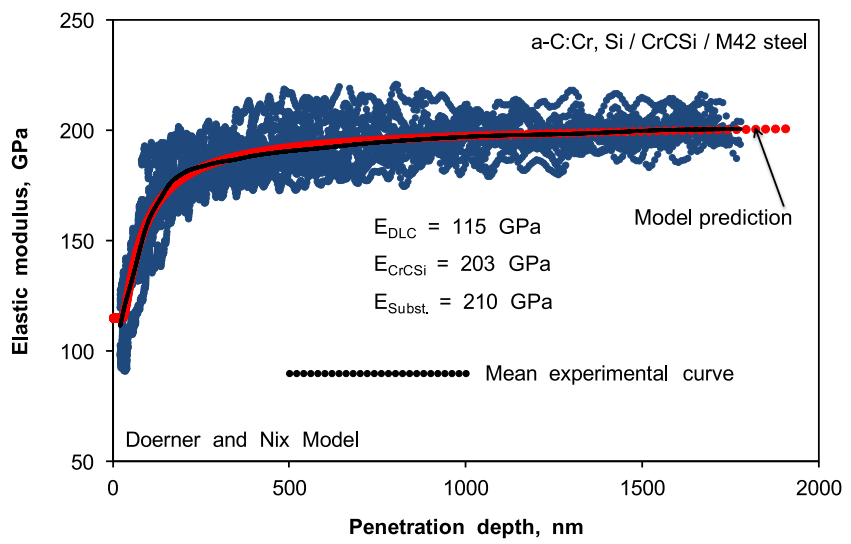

Fig. 3. Change in the elastic modulus with penetration depth for the a-C:Cr, Si/ CrCSi/M42 steel coated system, considering its bilayer architecture. The data have been described by means of the model advanced by Doerner and Nix [30], modified for multilayer coatings, as proposed by Puchi-Cabrera et al. [32]. The values of the elastic modulus computed for the individual layers are given on the plot. The elastic modulus of the steel substrate has been taken as $210 \mathrm{GPa}$.

\subsection{Coating elastic modulus}

Fig. 3 illustrates the change in the elastic modulus as a function of indentation depth, where again the experimental data are observed to remain within a wide scatter band of values. Therefore, the mean experimental curve has also been included in the plot. Since the calibration of the indenter for the elastic modulus revealed that in the case of the fused silica standard such a property is reproduced from penetration depths in the range of 7$10 \mathrm{~nm}$, only the experimental data points determined at indentation depths less than $20 \mathrm{~nm}$ were disregarded. Therefore, at low $h$ values the experimental value of the elastic modulus attains a magnitude of approximately $90 \mathrm{GPa}$. However, as the indentation depth increases the elastic modulus also increases and achieves a maximum value of about $220 \mathrm{GPa}$ at a depth of $800 \mathrm{~nm}$. As the indentation depth continues to increase, the elastic modulus tends to decrease to values in the range of 195-215 GPa, typical of the M42 steel substrate.

The description of this complex change in the coating elastic modulus was carried out by means of the extended form of the models earlier advanced by Doerner and Nix [30] and Menčík et al. [31], assuming, as before, that the coating is composed of two different layers. According to the extended model of Doerner and Nix [30], as proposed by Puchi-Cabrera et al. [32], the volume fraction of the doped DLC upper layer, $x_{\mathrm{v}}{ }^{\text {(DLC) }}$, which contributes to the composite modulus, should be computed in the following manner:

$x_{\mathrm{v}}^{(\mathrm{DLC})}=1$ if $\quad h<\frac{t_{\mathrm{f}}^{(\mathrm{DLC})}}{100}$

Otherwise:

$x_{\mathrm{v}}^{(\mathrm{DLC})}=1-\exp \left[-\alpha_{\mathrm{DN}}{ }^{(\mathrm{DLC})} \frac{t_{\mathrm{f}}{ }^{(\mathrm{DLC})}}{h-\frac{\left.t_{\mathrm{f}} \mathrm{(DLC}\right)}{100}}\right]$

In Eq. (7), $\alpha_{\mathrm{DN}}{ }^{\mathrm{DLC}}$, represents a material constant.

For the CrCSi layer underneath, its volume fraction, $\mathrm{x}_{\mathrm{v}}{ }^{(\mathrm{CrCSi})}$, is determined in the following manner:

$x_{\mathrm{v}}{ }^{(\mathrm{CrCSi})}=1-x_{\mathrm{v}}{ }^{(\mathrm{DLC})} \quad$ if $\quad \mathrm{h}<\frac{\left[t_{\mathrm{f}}{ }^{(\mathrm{DLC})}+\mathrm{t}_{\mathrm{f}}{ }^{(\mathrm{CrCSi})}\right]}{100}$
Table 3

Constants involved in the Doerner and Nix model for the bi-layer doped DLC and CrCSi film deposited onto a M42 steel substrate.

\begin{tabular}{ll}
\hline$E^{(\mathrm{DLC})}$ & $115 \mathrm{GPa}$ \\
$\alpha_{\mathrm{DN}}{ }^{(\mathrm{DLC})}$ & 0.016 \\
$E^{(\mathrm{CrCSi})}$ & $203 \mathrm{GPa}$ \\
$\alpha_{\mathrm{DN}}{ }^{(\mathrm{CrCSi})}$ & 1.536 \\
$E_{\text {Subst. }}$ & $210 \mathrm{GPa}$ \\
\hline
\end{tabular}

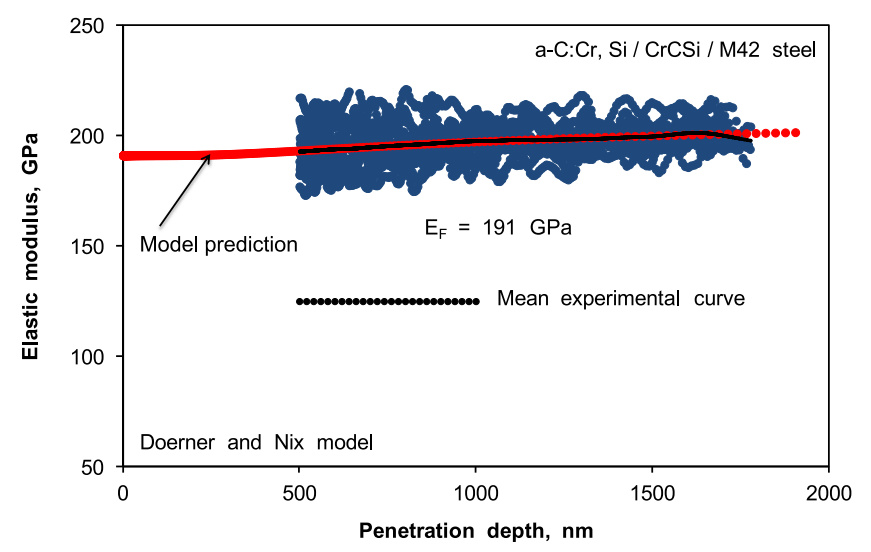

Fig. 4. Change in the elastic modulus with penetration depth for the a-C:Cr, $\mathrm{Si} /$ CrCSi/M42 steel coated system, assuming that the coating is a monolayer film. The data have been described by means of the model advanced by Doerner and Nix [30]. The value of the elastic modulus computed for the film is given on the plot. The elastic modulus of the steel substrate has been taken as $210 \mathrm{GPa}$.

\section{Otherwise:}

$\mathrm{x}_{\mathrm{v}}{ }^{(\mathrm{CrCSi})}=1-\exp \left[-\alpha_{\mathrm{DN}}{ }^{(\mathrm{CrCSi})} \frac{\left[\mathrm{t}_{\mathrm{f}}{ }^{(\mathrm{DLC})}+t_{\mathrm{f}}{ }^{(\mathrm{CrCSi})}\right]}{h-\frac{\left[\mathrm{t}_{\mathrm{f}}{ }^{(\mathrm{DLC})}+t_{\mathrm{f}}{ }^{(\mathrm{CrCSi})}\right]}{100}}\right]-\mathrm{x}_{\mathrm{v}}{ }^{(\mathrm{DLC})}$

Again, in Eq. (9), $\alpha_{\mathrm{DN}}{ }^{(\mathrm{CrCSi})}$ represents another material constant. Both $\alpha_{\mathrm{DN}}{ }^{(\mathrm{DLC})}$ and $\alpha_{\mathrm{DN}}^{(\mathrm{CrCSi})}$ are determined from the experimental $E$ versus $h$ data. Fig. 3 also illustrates the description predicted by this model and the elastic modulus values that were determined for both layers. Table 3 summaries the values involved in the model.

The elastic modulus predicted for the doped DLC coating of approximately $115 \mathrm{GPa}$ is close to that reported by Zou et al. [12], of approximately $108 \mathrm{GPa}$, for a DLC coating with about 10.5 at\% $\mathrm{Cr}$ and much less than the values reported by Jantschner et al. [15] for $\mathrm{a}-\mathrm{C}, \mathrm{a}-\mathrm{C}: \mathrm{Cr}$ and a-C:Si coatings, in the range of 144-189 GPa.

However, if the analysis of the elastic modulus is incorrectly conducted on the basis of the ISO 14577-4 standard, by disregarding the data points corresponding to indentation depths less than $500 \mathrm{~nm}$ and considering the coating as a monolayer film, entirely different results are obtained with the Doerner and Nix model [30], as illustrated in Fig. 4. In this case, the composite elastic model, $E_{\mathrm{C}}$, is expressed as:

$\frac{1}{\mathrm{E}_{\mathrm{C}}}=\frac{1-\exp \left[-\frac{\alpha_{\mathrm{DN}} \mathrm{t}_{\mathrm{F}}}{h}\right]}{\mathrm{E}_{\mathrm{F}}}+\frac{\exp \left[-\frac{\alpha_{\mathrm{DN}} \mathrm{t}_{\mathrm{F}}}{h}\right]}{\mathrm{E}_{\text {Subst. }}}$

Table 4 summarizes the value of the different constants involved in the above equation.

It can be clearly observed that the doped DLC coating exhibits an elastic modulus of approximately $191 \mathrm{GPa}$, which is quite close to the value reported by Jantschner et al. [15] for a a-C:Si coating, of about $189 \pm 5 \mathrm{GPa}$. Also, the value found employing this method would be close to that expected for a DLC with approximately 
Table 4

Constants involved in the Doerner and Nix model assuming a monolayer film deposited onto the M42 steel substrate.

\begin{tabular}{ll}
\hline$E_{\mathrm{F}}$ & $191 \mathrm{GPa}$ \\
$\alpha_{\mathrm{DN}}$ & 0.456 \\
$E_{\text {Subst. }}$ & $210 \mathrm{GPa}$ \\
\hline
\end{tabular}

Table 5

Mechanical properties of the different materials, which compose the coated system, employed in the computation of elastic stresses under spherical indentation loading. The tensile strength in each case is assumed to be one third of the hardness.

\begin{tabular}{lllll}
\hline & $\mathrm{a}-\mathrm{C}: \mathrm{Cr}, \mathrm{Si}$ & $\mathrm{CrSiC}$ & $\mathrm{M} 42$ steel & $\mathrm{Al}_{2} \mathrm{O}_{3}$ ball \\
\hline$\nu$ & $0.30[33]$ & $0.2[34]$ & 0.33 & 0.231 \\
$E, \mathrm{GPa}$ & 3700 & 5700 & 210 & 416 \\
$\sigma, \mathrm{MPa}$ & & 2667 & \\
\hline
\end{tabular}

5 at\% Cr, as reported by Zou et al. [12]. Very similar results would be obtained by means of the model advanced by Menčík et al. [31], which predicts an elastic modulus value of approximately $189 \mathrm{GPa}$.

The characterization of the change in the coating elastic modulus as a function of penetration depth taking into account the actual coating architecture is of fundamental importance for the correct computation of the change in the von Mises stress with distance from the surface, under the normal load applied, which represents the basis of the prediction of the coating behavior under spherical indentation loading and the interpretation of the sliding wear tests.

\subsection{Determination of the elastic contact stresses during spherical indentation}

The change in the von Mises stress with distance from the coating surface can be readily determined from the description provided by the modified Doerner and Nix model (Fig. 3) of the change in the elastic modulus with penetration depth for the coated system under investigation, as well as the values of Poisson ratio and tensile strength of the substrate and the two different layers, which compose the coating. The mechanical properties employed in this computation are summarized in Table 5. The Poisson ratios of the $\mathrm{a}-\mathrm{C}: \mathrm{Cr}, \mathrm{Si}$ and $\mathrm{CrSiC}$ films were obtained from the literature, whereas their tensile strengths were estimated as one third of their corresponding absolute hardness.

The computation of the change in the von Mises stress with distance from the surface was carried out on the basis of the Hertzian equations, which correspond to the elastic contact between a spherical indenter and a multi-layer coating. For this purpose, the strain compatibility at each interface was taken into consideration. The simplest way in which this objective was achieved implied the assumption that the principal strains at each interface, computed as a function of the von Mises stresses and elastic constants of the corresponding layer material, remained constant across each interface.

Therefore, the value of the elastic modulus was interpolated directly from the results shown in Fig. 3 and both the von Mises stresses and maximum pressure could be re-computed for the subsequent layer.

Thus, by interpolating the predicted values of the elastic modulus from the modified Doerner and Nix model, it is possible to solve the non-linear equation, which allows the determination

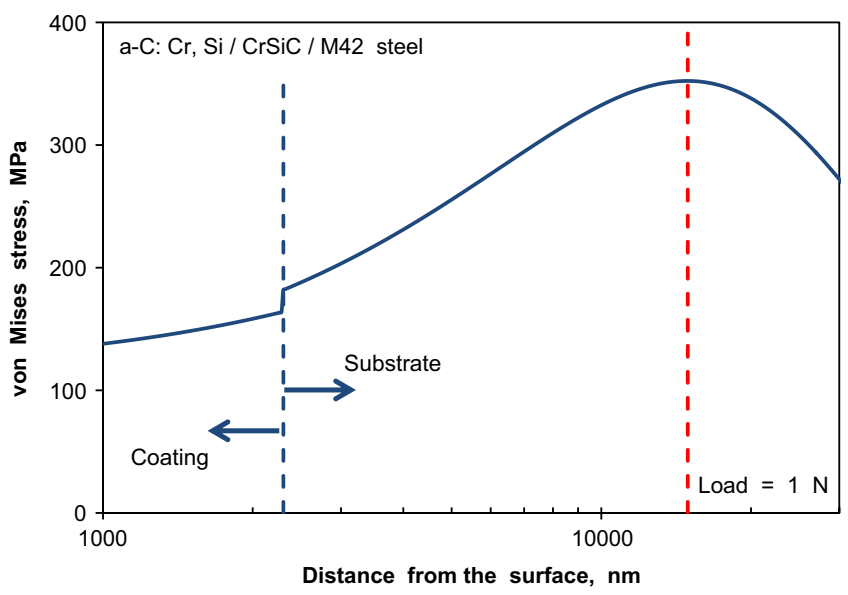

Fig. 5. Change in the von Mises stress as a function of the distance from the surface for the investigated coated system under spherical indentation loading.

of the contact radius (a) as a function of the reduced modulus $\left(E_{\mathrm{r}}(a)\right)$, load applied $(F)$ and indenter diameter $(d)$. Such an equation can be expressed as:

$f(a)=a-\left[\frac{3 F d}{8 E_{\mathrm{r}}(a)}\right]^{\frac{1}{3}}$

On the other hand, concerning the computation of the principal stresses and the von Mises stress, the Poisson ratio as a function of distance from the surface, was calculated assuming a Heaviside step function of the form:

$F(h, \alpha, \beta)=\frac{1}{2}\left[1+\tanh \left(\frac{\mathrm{h}-\alpha}{\beta}\right)\right]$

where $h$ represents the indentation depth and $\alpha$ and $\beta$ parameters of the step function. Details of the equations employed in the computation of the principal stresses can be found elsewhere [35].

The results of these computations are shown in Fig. 5 for $1 \mathrm{~N}$ applied load. As pointed out before, such a low load provides a contact pressure of approximately $540 \mathrm{MPa}$, characteristic of the maximum pressures found in an aluminum die extrusion press during operation. Fig. 5 clearly illustrates that under these testing conditions and at room temperature, the system is expected to behave elastically. At any distance from the surface, the von Mises stress is well below the strength of the a-C:Cr, Si film, of approximately $3700 \mathrm{MPa}$ and the maximum von Mises stress value, of $505 \mathrm{MPa}$, is attained at a distance of about $14890 \mathrm{~nm}$, that is to say, well into the M42 steel substrate, whose mechanical strength is also significantly higher. However, the predictions indicate that even up to load in the range of $40 \mathrm{~N}$, that it to say maximum contact pressures of approximately $1885 \mathrm{MPa}$, the coated system would behave elastically at room temperature without failure.

\subsection{Scratch test results}

The results from the scratch test conducted on this coating are presented in Fig. 6, which shows the variation of both friction force and acoustic emission signal as the normal load increases during the test. The failures that occur on the sample surface correspond to a sudden change in these two parameters that take place as the diamond stylus is displaced on top of the coating.

The important variations in the values of these parameters are also correlated with the corresponding events that could have taken place from the morphological point of view, by means of an optical microscope attached to the system. The load Lc3 $=54 \mathrm{~N}$ 

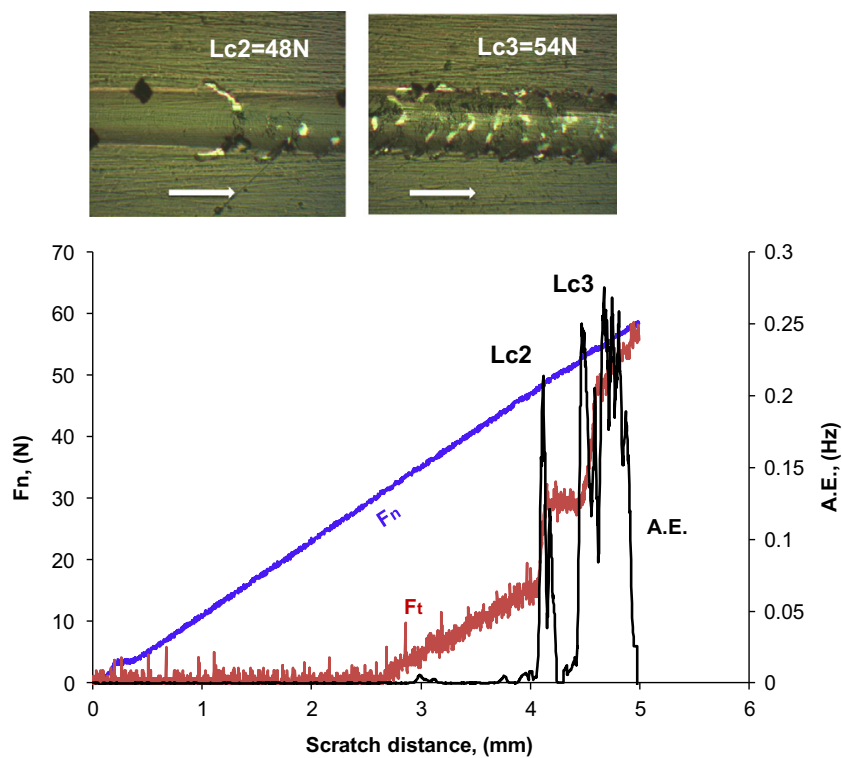

Fig. 6. Variation of the friction force and acoustic emission signal as the normal load increases along the scratch track. The micrographs indicate the morphology of the track for each characteristic failure.

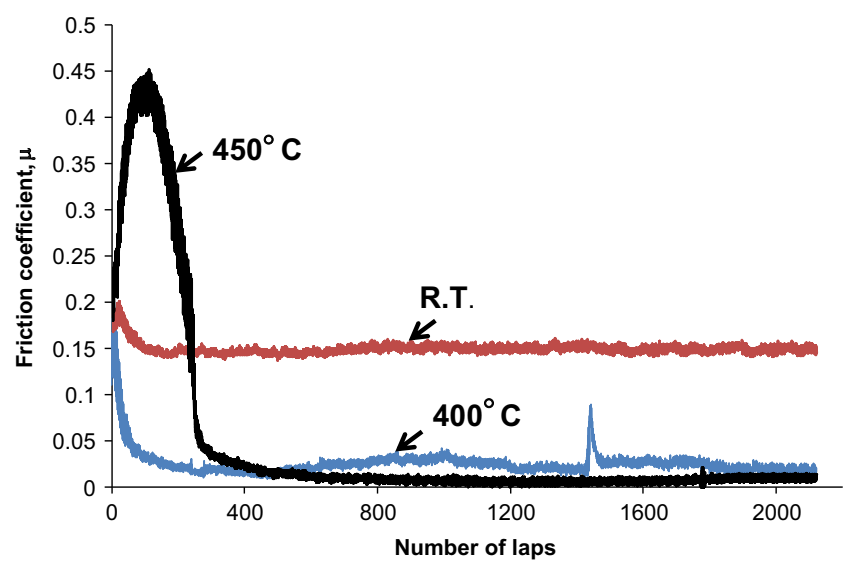

Fig. 7. Variation of the friction coefficient with the number of laps at: (a) RT; (b) $400^{\circ} \mathrm{C}$; (c) $450{ }^{\circ} \mathrm{C}$.

marked on Fig. 6 is considered as the critical value for coating gross interfacial shell-shaped spallation [36], that is to say, detachment from which uncovered substrate was seen regularly. On the other hand, Lc $2=48 \mathrm{~N}$ corresponded to the load where interfacial spallation started to occur at the borders of the scratch. The acoustic emission signal coincided very well with the changes that occurred in the friction force value. Therefore, it allows the precise detection of the characteristic values for these adhesive failures. The determined values compare well with those reported in the literature [37] for standard a-C coatings (Graphit-iCтM) produced by sputtering.

\subsection{Wear test results}

\subsubsection{Friction coefficients}

The representative variation of the friction coefficient with the number of laps at different testing temperatures is shown in Fig. 7, where some selected curves are included. It can be observed that the rate of change in the value of the friction coefficient at the beginning of the test is high, but much more pronounced in the case of the tests conducted at $400{ }^{\circ} \mathrm{C}$, for example, as compared with those carried out at room temperature. During the wear tests, it is considered that the properties of the counterpart, as well as those corresponding to the substrate were unchanged.

The value of the friction coefficient of the a-C:Cr,Si coating at RT. determined in the present work at the beginning of the test is observed to be approximately 0.2. Subsequently, it drops to a steady state value of 0.15 after 100 laps, until the end of the test. This value compares well with that of 0.13 reported for a standard a-C: $\mathrm{Cr}$ coating of $2.2 \mu \mathrm{m}$ thickness, tested against alumina ball of $6 \mathrm{~mm}$ diameter at a normal load of $10 \mathrm{~N}$ [15]. This comparison can be done, although the normal loads are different, since it has been shown recently [38] that, during wear tests against a $6 \mathrm{~mm}$ alumina ball, the friction coefficient of a-C films decreases slowly from 0.117 to approximately 0.1 , as the load applied increases from 1 to $10 \mathrm{~N}$. These authors have attributed this decrease to a higher graphitization level induced by higher contact stresses. Additionally, a decrease in the wear rate from $10^{-7} \mathrm{~mm}^{3} / \mathrm{N} \mathrm{m}$ to approximately half of this value, i.e. $0.45 \times 10^{-7} \mathrm{~mm}^{3} / \mathrm{N} \mathrm{m}$ for the same interval of the applied load, has also been reported. However, it has to be mentioned that the presence of humid air $(40 \pm 5 \%$ relative humidity in this research) during the wear tests gives rise to low values of the friction coefficient.

In the present work, the relative humidity was only controlled during the low temperature tests. However, for the tests performed at high temperatures no control was carried out. The factors, which give rise to a low friction coefficient value, as well as low wear rates at both room and high temperatures, are completely different. It is well known that, at room temperature, the behavior of hydrogen-free DLC films is strongly dependent on the presence of humidity, since the adsorption and dissociation of water molecules change completely the nature of the bonds and its surface chemistry $[39,40]$. Under these conditions, it is expected that the coating will have a better performance. On the other hand, an increase in temperature will have a contrary effect, since the desorption of the water vapors will give rise to an increase in the friction coefficient [39]. However, at high temperatures the silicon oxidation, as well as graphitization of the coating, takes place, which will have a significant influence of the on the evolution of the friction coefficient, as explained in the forthcoming.

Thus, as the test temperature increases to $400{ }^{\circ} \mathrm{C}$, the friction coefficient during the running in period drops, after 166 laps, from 0.18 to 0.02 . This value is also found at the end of the test but, as can be seen from the evolution of the friction coefficient with the number of laps, at about 1440 laps, the friction coefficient increases suddenly to a value of 0.08 , after which it decreases to its steady state constant value of 0.02 , a fact that could be eventually related to the existence of some debris retained in the contact.

Finally, for the tests carried out at $450{ }^{\circ} \mathrm{C}$ the running in period is quite different, since the friction coefficient value increases from a starting point of 0.2 to a value of 0.42 after 100 laps. Subsequently, it decreases to a value of 0.05 after 256 laps. This increase can be probably associated to a series of oxidation reactions that take place on the coating surface, at the beginning of the test, leading in the end to a surface that is totally oxidized and, hence, providing the characteristics of a lubricious film in contact with the alumina ball. Only after 600 laps, a steady state value of 0.01 is achieved and maintained until the end of the test. These values for the friction coefficient are similar to those reported by Jantschner et al. [15] at a temperature of $450^{\circ} \mathrm{C}$. However, in the present case the friction coefficient values did not exhibit the high scatter reported by these authors, indicating that the addition of both $\mathrm{Si}$ and $\mathrm{Cr}$ conferred to the coating a better performance during contact.

It is important to point out that in order to understand the possible mechanisms responsible of the very low friction coefficient values determined at high temperatures, the wear tests "per se" are not enough and should be coupled with additional 
analyses such as Raman spectroscopy and XPS. These techniques should be carried out on both counterparts in a "post facto" stage or after any important event taking place during the wear tests.

However, taking into account the findings reported in the literature, as well as the behavior of the coating components at high temperatures, it is possible to hypothesize that, as the test temperature increases from $25^{\circ} \mathrm{C}$ to $400{ }^{\circ} \mathrm{C}$ and $450{ }^{\circ} \mathrm{C}$, respectively, the silicon present in the coating composition will be oxidized, due to its high affinity to oxygen. Fountzoulas et al. [41] carried out RBS analysis on annealed surfaces of Si-DLC and were able to show that silicon oxidation could take place at the outer surface of the coating, at temperatures as low as $200{ }^{\circ} \mathrm{C}$.

Also, as indicated by Gharam et al. [11], when studying the influence of temperature on the tribological behavior of $\mathrm{W}$ containing DLC, silicon oxidation, proportional to the increase in temperature, occurred in parallel with carbon depletion. At $400{ }^{\circ} \mathrm{C}$ the extent of oxidation is smaller than that corresponding at $450{ }^{\circ} \mathrm{C}$, as explained in the next section. At this latter temperature the oxidation kinetic is more important and different oxidation products such as silicon oxide [42], Si-O or Si-OH have been reported to have lubricious properties [15].

However, at $450{ }^{\circ} \mathrm{C}$ a rapid increase in the friction coefficient takes place in the running-in period, before stabilization, since possibly a high amount of silicon oxide will be in contact with alumina from the ball, until other factors come into play. It has also been shown [13] that a change of the a-C structure takes place as the temperature exceeds $300{ }^{\circ} \mathrm{C}$ and that a complete graphitization will occur at temperatures higher than $500{ }^{\circ} \mathrm{C}$ [11].

Moreover, Choi et al. [43], when studying the effect of Si incorporation and annealing temperature on the tribological behavior of DLC coatings, have indicated the growth of graphitic islands in the annealed DLC films, which have low \%Si. These authors attributed the low friction coefficients to the low shear strength of the graphitized surfaces, as well as to the exchange of silicon oxide with the counterpart.

In the present case, in order to explain the low friction coefficients, it could be probably considered that both phenomena (presence of graphite in the contact and its subsequent transfer to the alumina ball) coupled with the exchange of silicon oxidation products with the ball, took place. In this way, the contact of the alumina ball with the DLC coating has been hindered, contributing therefore, to a decrease in the friction coefficient value. In both cases the increase in temperature is expected to influence the kinetics of such processes.

For comparison, 3D surface profiles are presented in Fig. 8a for all the tests, whereas Fig. 8b illustrates the corresponding cross section profiles of the wear track, where both the experimental and computational description of the profiles are represented. It has to be mentioned that the calculation was carried out by considering that the zero depth position is that which corresponds to the initial measurement of the $2 \mathrm{D}$ profile. The average values of the cross section areas computed for the profiles measured across the wear track are presented in Table 6, together with the wear constants values in each case.

It is observed that the cross section area of the coating tested at $25^{\circ} \mathrm{C}$ is nearly one order of magnitude less than those corresponding to the samples tested at $400^{\circ} \mathrm{C}$ and $450{ }^{\circ} \mathrm{C}$, respectively. However, it is interesting to point out that, from the analysis of the wear track profiles, the coated sample tested at $400{ }^{\circ} \mathrm{C}$ had a wear rate approximately 3 times higher than that tested at $450{ }^{\circ} \mathrm{C}$.

The higher resistance to wear at this higher temperature could be probably attributed to the presence of both $\mathrm{SiC}$ and $\mathrm{CrC}$ nanocrystallites, the later in a higher amount, formed during deposition, which could eventually have maintained the coating hardness. Similar considerations were done by Zang et al. [13] when studying the thermal stability of a $\mathrm{Ti}$ and $\mathrm{Al}$ doped a-C sputtered
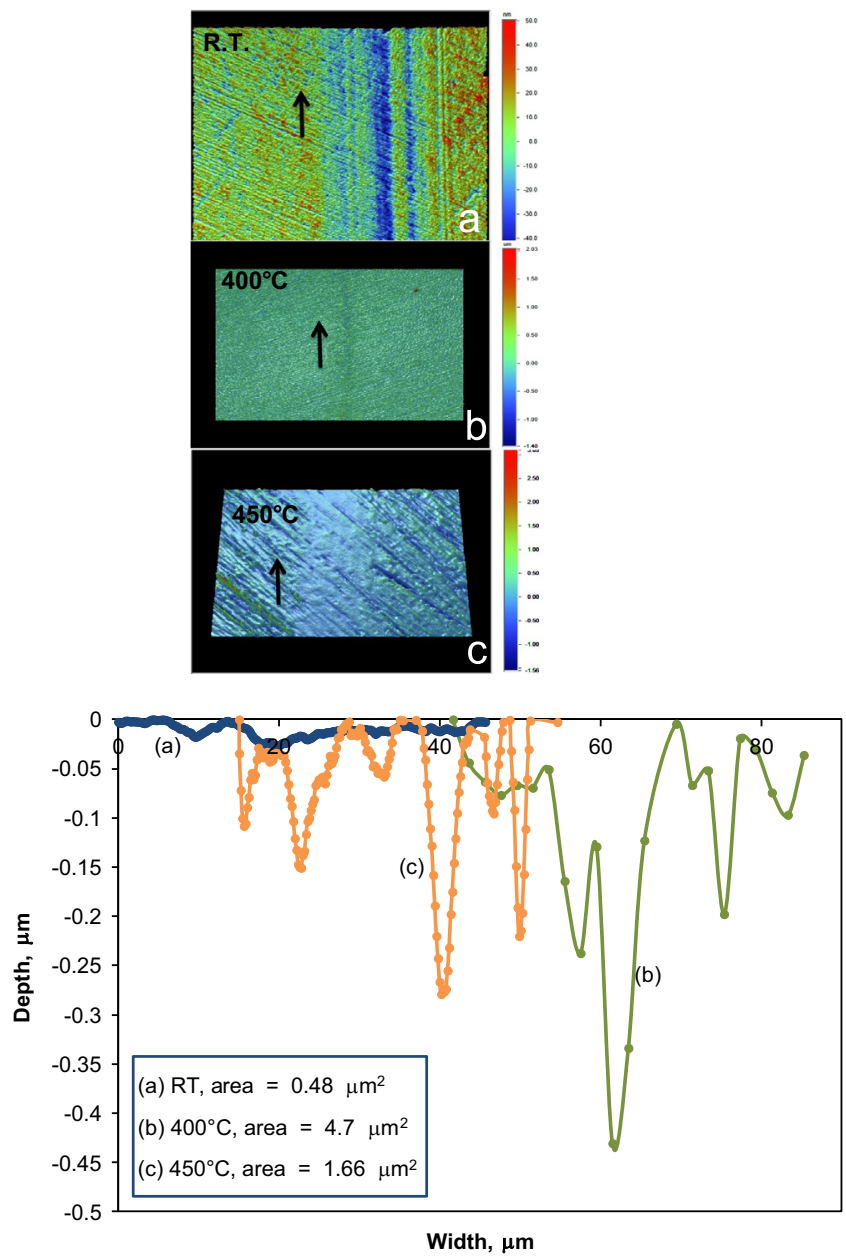

Fig. 8. (a) 3D profiles corresponding to: (a.) wear track at room temperature (RT); (b.) wear track at $400{ }^{\circ} \mathrm{C}$; (c.) wear track at $450{ }^{\circ} \mathrm{C}$. The direction of the wear scars are indicated on each profile. (b) 2D depth profiles corresponding to the different wear scars shown in Fig. 8a.

Table 6

Results from the wear tests.

\begin{tabular}{llll}
$\begin{array}{l}\text { Test tempera- } \\
\text { ture }\left[{ }^{\circ} \mathrm{C}\right]\end{array}$ & $\begin{array}{l}\text { Average cross } \\
\text { section area } \\
{\left[\mu \mathrm{m}^{2}\right]}\end{array}$ & $\begin{array}{l}\text { Average wear volume } \\
{\left[10^{-16} \mathrm{~m}^{3}\right]}\end{array}$ & $\begin{array}{l}\text { Wear rate constant } \\
{\left[10^{-19} \mathrm{~m}^{3} /\right.} \\
(\mathrm{N} \times \mathrm{No} . \mathrm{laps})]\end{array}$ \\
\hline 25 & $0.48 \pm 0.04$ & $0.67 \pm 0.04$ & $0.35 \pm 0.04$ \\
400 & $4.7 \pm 0.32$ & $6.63 \pm 0.32$ & $3.42 \pm 0.32$ \\
450 & $1.66 \pm 0.27$ & $2.33 \pm 0.27$ & $1.2 \pm 0.27$ \\
\hline
\end{tabular}

coating. These authors indicated that the presence of TiC nanocrystallites were able to maintain the coating hardness until $600{ }^{\circ} \mathrm{C}$, without the coating thickness loss.

However, Raman spectroscopy conducted on sputtered a-C:Si and $\mathrm{a}-\mathrm{C}: \mathrm{Cr}$ coatings were not able to identify the presence of either $\mathrm{SiC}$ or $\mathrm{CrC}$, as reported before [15], although in the case of similar a-C coatings, where $\mathrm{Cr}$ was used as interlayer for adhesion improvement, the presence of $\mathrm{CrC}$ was identified in the graded layer before growing the proper DLC coating for a $\mathrm{Cr}$ content just as small as $2 \%$ [17].

Although the wear behavior at high temperatures of DLC coated systems has been studied to some extent [9-12,15,43], a direct comparison of the present results with those reported previously is not straightforward due to a number of reasons, which include: testing conditions, nature of the coating and concentration of doping elements, among others. As an example, the 
work of Jantschner et al. [15] involved the investigation of the wear behavior of three different systems, which comprised: $\mathrm{a}-\mathrm{C}$, $\mathrm{a}-\mathrm{C}: \mathrm{Cr}$ and a-C:Si coatings of a similar thickness.

As in the present work, these systems were tested up to temperatures of $450{ }^{\circ} \mathrm{C}$, but with an applied load of $10 \mathrm{~N}$, a coating thickness in the range of $1.8-2.1 \mu \mathrm{m}$, a number of laps between 1000 and 2500 and an alumina counterpart of $6 \mathrm{~mm}$. Therefore, the initial Hertzian contact pressure found in these experiments achieved approximately $1.6 \mathrm{GPa}$. According to these authors, the a-C: $\mathrm{Cr}$ coating was not able to withstand the above testing conditions, which resulted in a high wear rate. On the contrary, the a-C:Si coating was able to perform satisfactorily up to a temperature of $450{ }^{\circ} \mathrm{C}$.

In the present work, it is shown that the a-C:Cr, Si coating is also able to perform satisfactorily up to temperatures of $450^{\circ} \mathrm{C}$, although the wear rates that have been determined (Table 6) are two order of magnitude smaller than those reported by Jantschner et al. [15]. Nevertheless, this comparison is not strictly appropriate due to the difference in the testing conditions of both investigations. However, an interesting feature shown by both research works is that doped a-C coatings either with $\mathrm{Si}$ or $\mathrm{Cr}$ and $\mathrm{Si}$, could be promising candidates to be employed in metalworking processes conducted in the range of temperatures that has been explored, as for example, in the extrusion aluminum industry.

\subsubsection{Morphology of the wear scars}

Figs 9 through 11 show the morphology of the wear tracks obtained by scanning electron microscopy coupled with EDS analysis.

Fig. 9 illustrates a secondary electron image and two magnified detailed areas, corresponding to the wear track that resulted from the test carried out at room temperature (RT). The Figure also includes the elemental EDS maps of the whole area shown in Fig. (9c) for the different elements that were analyzed: $\mathrm{C}, \mathrm{O}, \mathrm{Cr}, \mathrm{Si}$, $\mathrm{Ar}$ and $\mathrm{Fe}$, respectively. From this Figure it can be seen that the coating is almost undamaged, as shown by the $C$ map. Also, it can be observed that it contains an important \% of $\mathrm{Ar}$ and $\mathrm{Cr}$, in a higher amount than $\mathrm{Si}$ and an imperceptible amount of $\mathrm{O}$. The presence of Fe from the substrate is also shown, since it is well known that the penetration depth of the X-ray probe during EDS analysis for a carbon sample, at $20 \mathrm{keV}$ of accelerating voltage, achieves about $6 \mu \mathrm{m}$.

Fig. 10 presents the SEM micrograph of the wear track at $400^{\circ} \mathrm{C}$, as well as the corresponding mapping carried out, indicating the presence of a higher amount of oxygen and silicon that
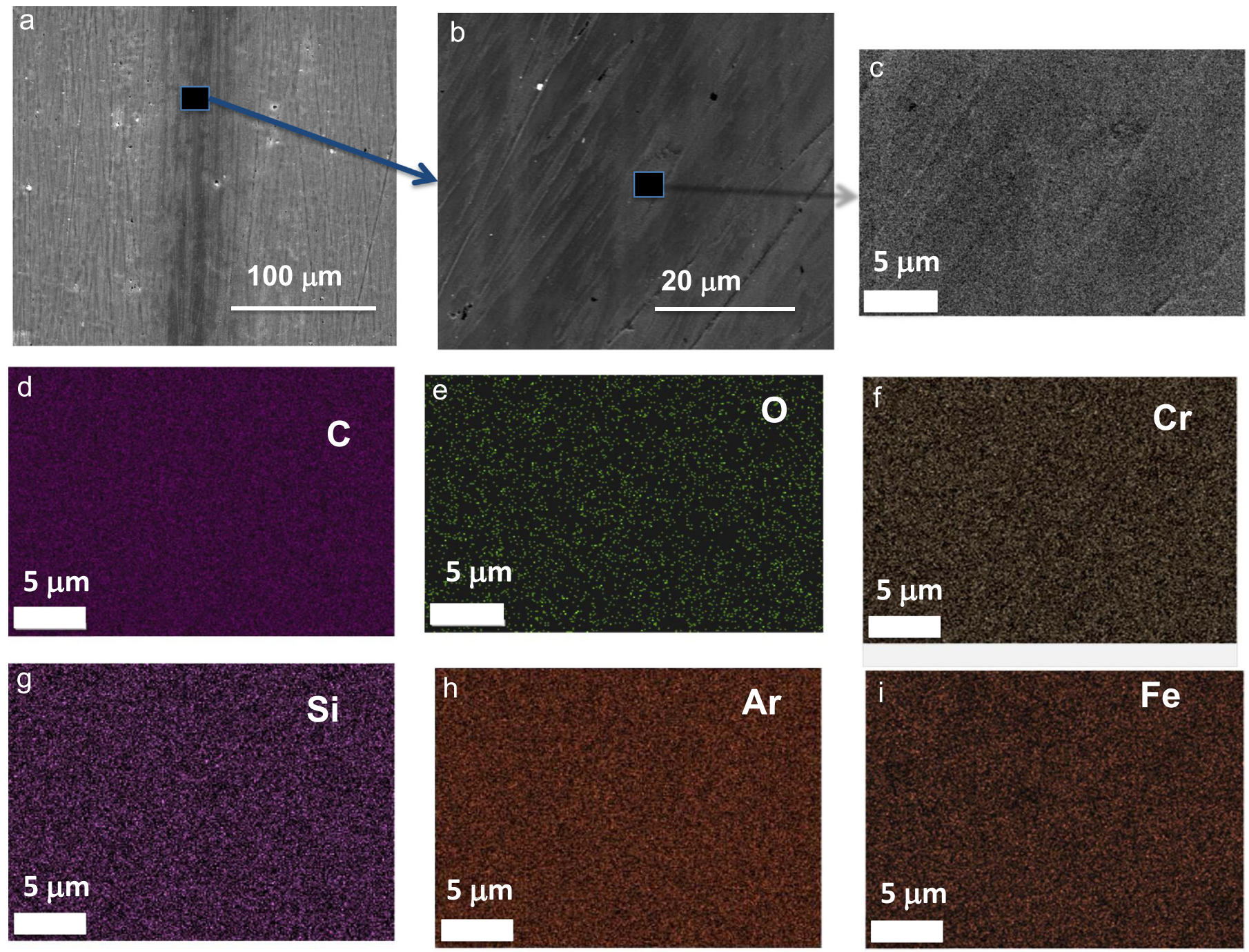

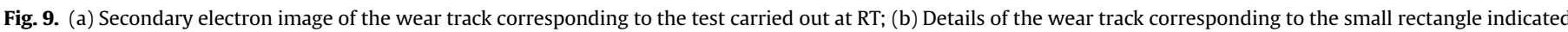

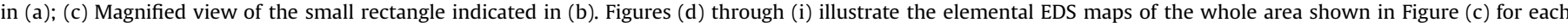
element: C, O, Cr, Si, Ar and Fe, respectively. 

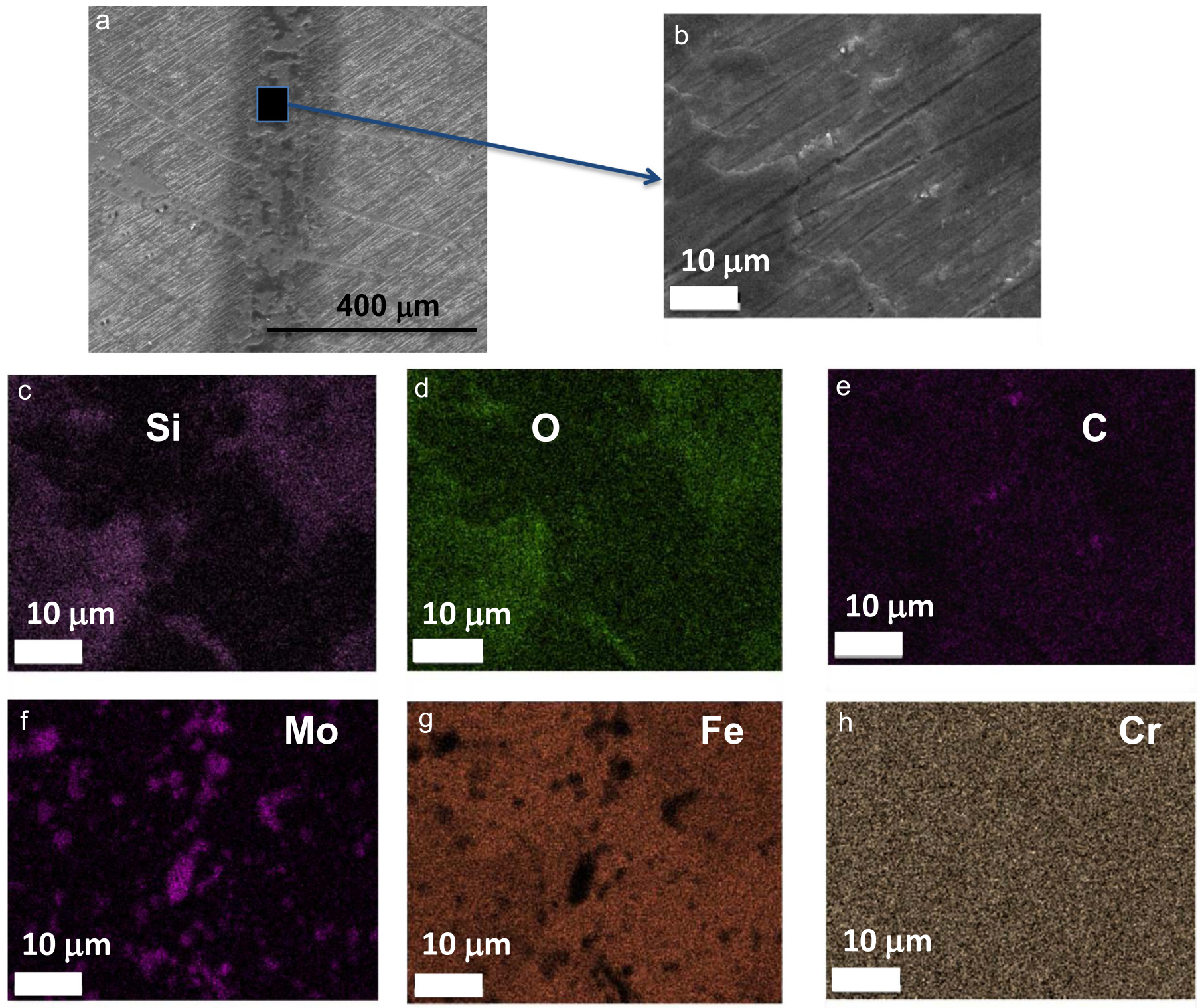

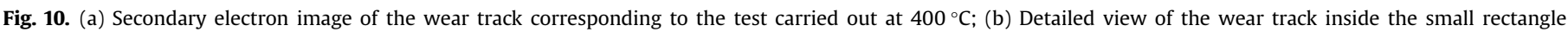

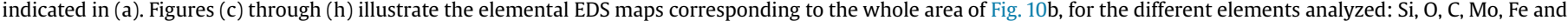
$\mathrm{Cr}$, respectively.

cover part of the coating surface, as shown in Fig. 10b. The $\mathrm{Cr}$ map indicates that the coating was not penetrated, but its thickness has been reduced, since a higher amount of $\mathrm{Fe}$, as well as Mo are present, as compared to the mapping of the wear track of the coating tested at RT.

The amount of oxidation at $450{ }^{\circ} \mathrm{C}$ is significantly greater than at $400{ }^{\circ} \mathrm{C}$, pointing out that, in the former case, a continuous oxide film was formed. Moreover, it can be seen from the micrograph presented in Fig. 11c that the oxidation process was accompanied by the presence of a high amount of cracks on the coating surface.

In order to calculate the relative variation of the atomic concentration of elements such as $\mathrm{O}, \mathrm{Si}, \mathrm{Cr}$ and $\mathrm{Fe}$, which indicate the important changes that take place during the tests, EDS analyses were performed on SEM images of the worn track surfaces of the samples tested at $25^{\circ} \mathrm{C}, 400{ }^{\circ} \mathrm{C}$ and $450{ }^{\circ} \mathrm{C}$, respectively. Table 7 presents the percentage relative variation of the above elements as a function of the wear test temperature. The spectra were quantified to determine the weight percentage using the eZAF method. The results indicate, besides those elements mentioned above, the presence of $\mathrm{C}$ and Ar. Therefore, the recalculation of the concentrations on the $100 \%$ basis for all samples was considered, without taking into account the existence of $\mathrm{C}$ and Ar. This proposed procedure is based on the fact that the amount of oxygen found in the wear track at high temperatures corresponds to that present in the oxides that were formed during the tests, since part of the $\mathrm{C}$ will already be oxidized to $\mathrm{CO}_{2}$ and expelled together with Ar during heating.

It has to be pointed out that these percentages calculated here do not correspond to their absolutes values, but provide a very important indication of the coating behavior during the wear tests. Also, it has to be considered that as the wear test temperature increases, the oxidation kinetics is different and that the reactions take place in parallel with the wear phenomenon. For example, it is shown that an important quantity of $\mathrm{Si}$ is present in the wear track of the coating tested at room temperature, since the M42 steel substrate has a very low content of Si, which varies between $0.15-0.65 \mathrm{wt} \%$. Also, the \% of $\mathrm{Cr}$ is much higher in the wear track at RT than that corresponding to the wear track obtained when the 

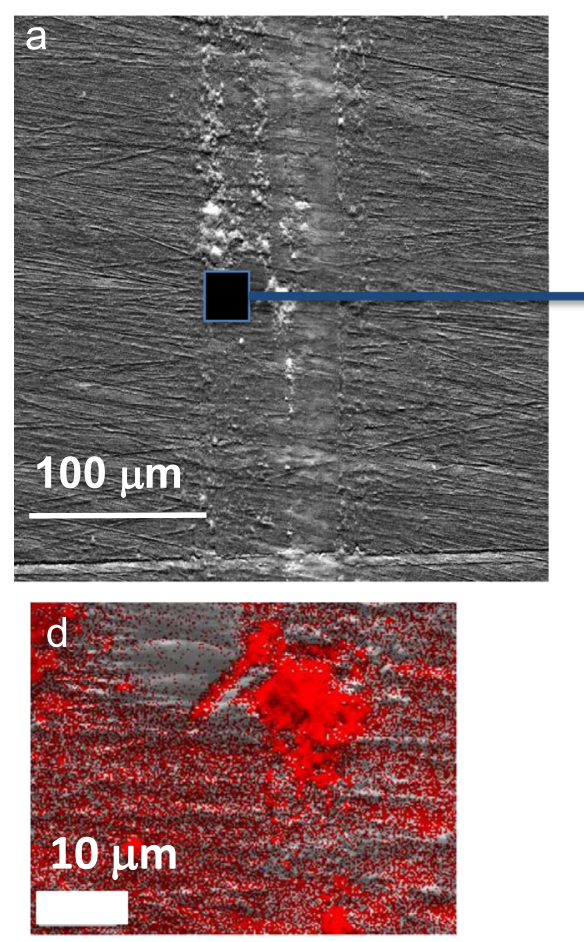

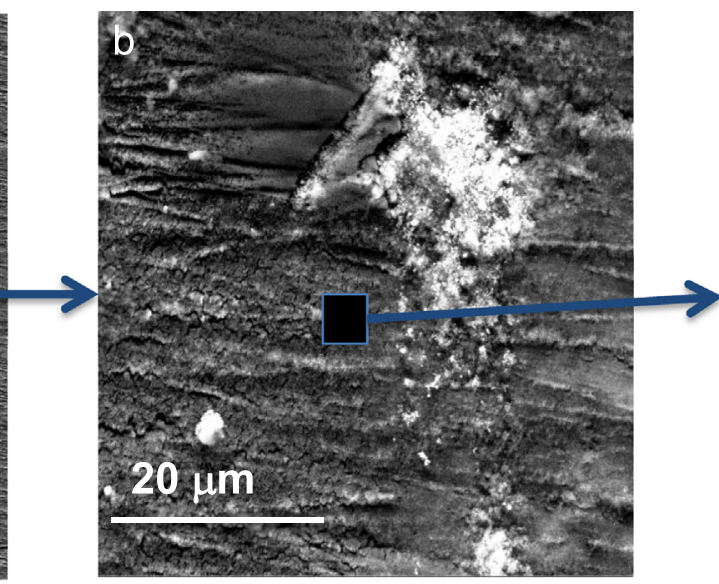

$57 \%$ o k/Sik/Crk (29121 Pixels)

$43 \%$ Unallocated (22079 pixels)

$0 \%$ Sum (256 Pixels)
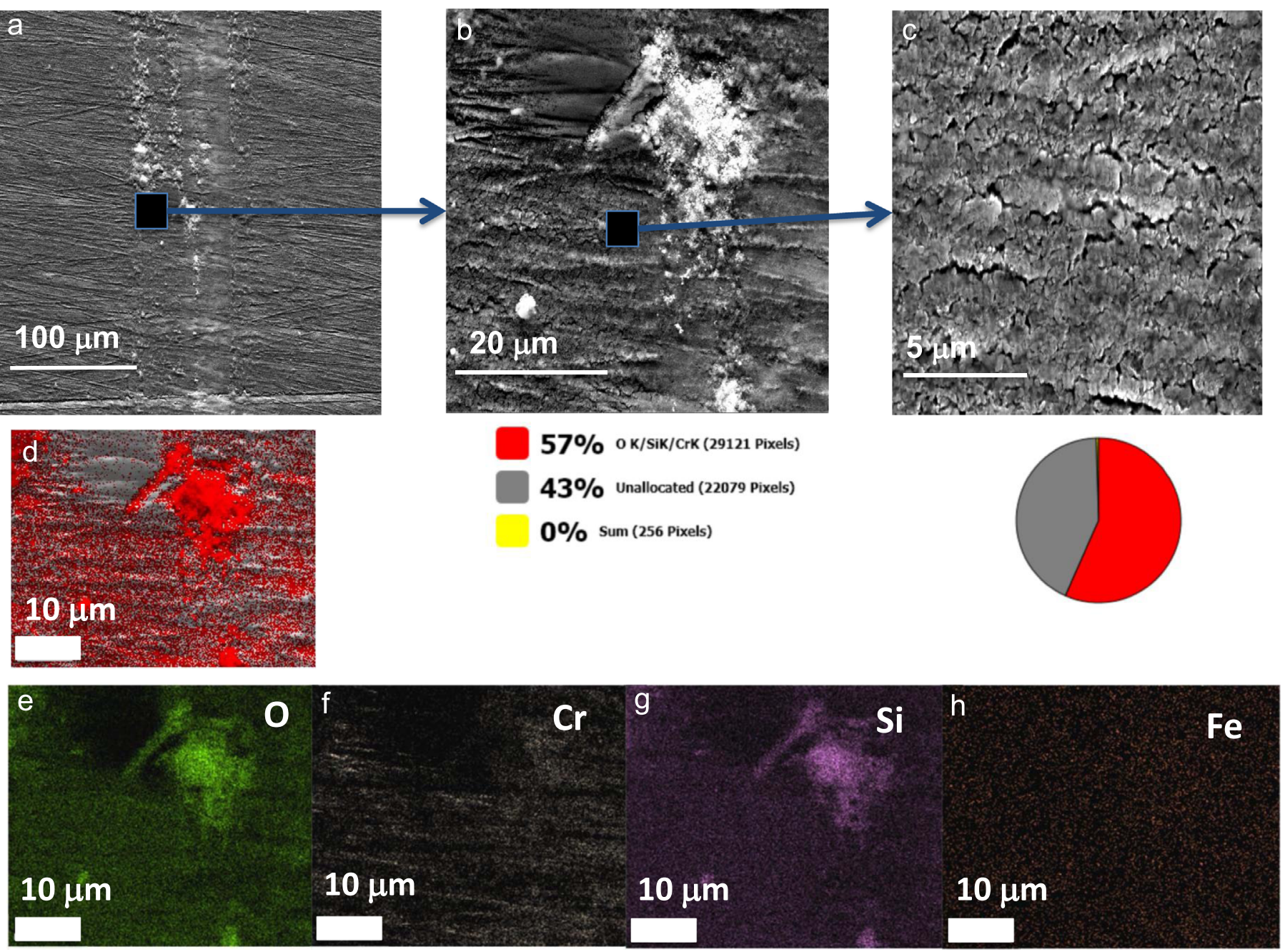

Fig. 11. (a) Secondary electron image of the wear track corresponding to the test carried out at $450{ }^{\circ} \mathrm{C}$; (b) Detail view of the wear track corresponding to the small rectangle indicated in Fig. 11a. (c) Detail view of the wear track corresponding to the small rectangle indicated in Fig. 11b. (d) Multi-element x-ray map. Figures (e) through (h) illustrate the EDS maps of the whole area corresponding to Fig. 11b for the different elements analyzed: O, Cr, Si and Fe, respectively.

Table 7

Relative variation of the elemental concentration of the coated system with the wear test temperature.

\begin{tabular}{lccc}
\hline Element (\%wt without \%C) & Test at $25{ }^{\circ} \mathrm{C}$ & Test at $400{ }^{\circ} \mathrm{C}$ & Test at $450{ }^{\circ} \mathrm{C}$ \\
\hline $\mathrm{O}$ & 1.5 & 11.8 & 25.2 \\
$\mathrm{Si}$ & 8.3 & 3.3 & 22.2 \\
$\mathrm{Cr}$ & 70.3 & 41.2 & 51.2 \\
$\mathrm{Fe}$ & 19.9 & 43.8 & 1.3 \\
\hline
\end{tabular}

coating was tested at $400{ }^{\circ} \mathrm{C}$, indicating that at this latter temperature some other oxides cover the coating surface. Also, that at $400{ }^{\circ} \mathrm{C}$ a higher wear volume was displaced, since the amount of Fe appeared to be nearly doubled as compared to the test carried out at RT. In this case, it has to be considered that the coating thickness could have decreased as consequence of the oxidation of $\mathrm{C}$ to form $\mathrm{CO}_{2}$ and, therefore, a higher influence of the substrate could appear during EDS analysis.

However, it is believed that at a temperature of $450{ }^{\circ} \mathrm{C}$ a thicker oxide layer is formed within the wear track and therefore, the Fe concentration would appear to be less.

As expected, it is also observed that as the temperature increases, the amount of oxygen will be higher, since the oxidation of the coating elements will take place as a function of both their affinity towards oxygen, as indicated by their Gibbs free energy of formation, and their process oxidation kinetics.

The existence of this relatively small amount of $1.5 \% \mathrm{O}$ at room temperature could probably correspond to the amount of $\mathrm{O}_{2}$ in these kind of coatings designed by Draxler et al. [16], where the percentage of oxygen and hydrogen is reported to be in general below 1.2 and 2 at\%, respectively.

As the test temperature increases to $450{ }^{\circ} \mathrm{C}$, a higher amount of oxidation takes place with an increase in the coating volume due to the oxidation process, which added to the elimination of $\mathrm{CO}_{2}+\mathrm{Ar}+\mathrm{H}_{2} \mathrm{O}$ as gases, could have given rise to severe surface cracking, as can be observed in Fig. 11c.

The micrographs shown in Fig. 12 illustrate the alumina counterpart, in contact with the coated sample, after the wear tests carried out at $25^{\circ} \mathrm{C}$ and $450{ }^{\circ} \mathrm{C}$, respectively. At $25^{\circ} \mathrm{C}$ a negligible wear of the counterpart was observed, as it can be noticed in Fig. 12a and a transferred layer is seen on top of the ball. At $450{ }^{\circ} \mathrm{C}$, as explained before, in addition to this transferred layer, it can be observed that the alumina ball has worn off during the test. The EDS mapping of this ball indicated the presence of $\mathrm{C}$ and $\mathrm{Si}$ on its surface. It is supposed that this phenomenon is a consequence of the contact between the oxidation products and the alumina counterpart during the running-in stage, since a friction coefficient value of approximately 0.42 is characteristic of a ceramic/ceramic contact. 
a

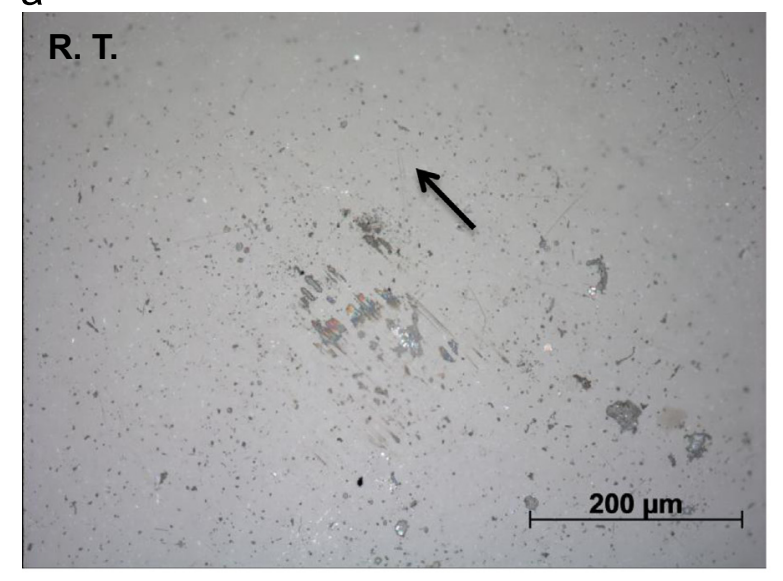

b

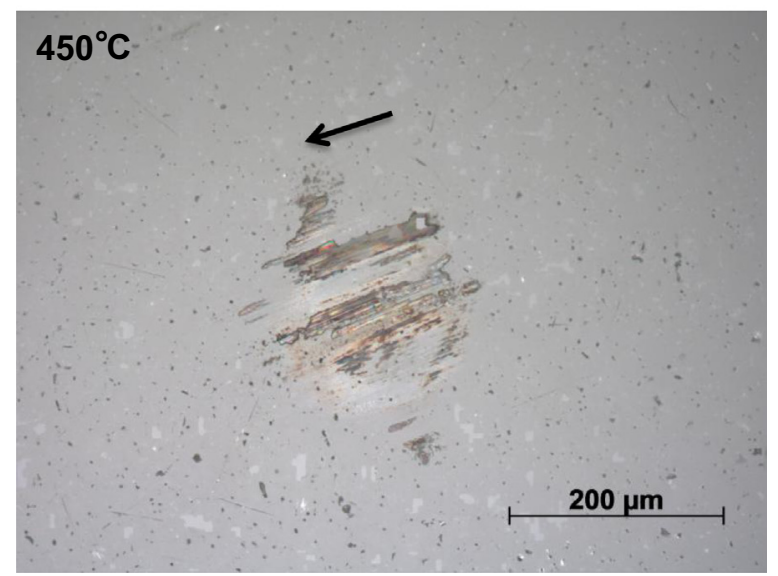

Fig. 12. Optical micrographs of the alumina counterpart after the wear tests carried out at: (a) $25^{\circ} \mathrm{C}$ and (b) $450{ }^{\circ} \mathrm{C}$. At $25^{\circ} \mathrm{C}$ a negligible wear of the counterpart and the presence of a transferred layer can be observed. At $450{ }^{\circ} \mathrm{C}$, besides the presence of the transferred layer, the wear of the alumina ball is quite noticeable. The EDS mapping of this ball indicated the presence of $\mathrm{C}$ and $\mathrm{Si}$ on its surface.

Nevertheless, further detailed studies by using different techniques such as Raman and Fourier Transform Infrared Spectroscopy (FTIR), as well as Focus Ion Beam (FIB) techniques coupled with EDS, should be used in order to determine precisely the nature and composition of the surfaces in contact, as well as the extent of the oxidation across the coating under the influence of the existing environment during the high temperature wear tests.

\section{Conclusions}

The results of the present investigation indicates that the prototype a-C coating doped with both $\mathrm{Cr}$ and $\mathrm{Si}$ in small quantities exhibits a low wear rate of approximately $1.2 \times 10^{-18} \mathrm{~m}^{3} / \mathrm{N}$ m at room temperature, which is approximately one order of magnitude and three times less than those found from the tests performed at $400{ }^{\circ} \mathrm{C}$ and $450{ }^{\circ} \mathrm{C}$, respectively. Steady state value of the friction coefficients were found to be of $0.15,0.02$ and 0.01 at RT, $400{ }^{\circ} \mathrm{C}$ and $450{ }^{\circ} \mathrm{C}$, respectively.

Under the tested conditions, the a-C: $\mathrm{Cr}, \mathrm{Si}$ coating exhibits a very good wear resistance even at a temperature of $450{ }^{\circ} \mathrm{C}$, without the coating loss, as consequence of the presence of an important amount of $\mathrm{Si}$ and $\mathrm{Cr}$ oxides due to the oxidation process. It was found from that the amount of oxidation at $450{ }^{\circ} \mathrm{C}$ is far more greater than at $400{ }^{\circ} \mathrm{C}$, indicating that, in the former case, a continuous oxide film was formed, which gave rise to a smaller wear rate. The increase in the coating volume due to the oxidation process at $450{ }^{\circ} \mathrm{C}$, together with the elimination of $\mathrm{CO}_{2}, \mathrm{Ar}$ and $\mathrm{H}_{2} \mathrm{O}$ vapor, gave rise to a severe surface cracking of the coating.

The hardness and elastic modulus of the a-C:Cr,Si/CrSiC/M42 bilayer coated system have been characterized by nanoindentation techniques and modeled by considering their actual architecture, as well as under the assumption of the existence of a monolayer film. The first approach allowed the precise determination of the actual mechanical properties values of each of the individual layers, which encompass the bilayer coating. Accordingly, the hardness and elastic modulus of the DLC film were found to be approximately 11 and $115 \mathrm{GPa}$, respectively, whereas those of the CrSiC layer were of about 17 and $203 \mathrm{GPa}$, respectively.

These values differs significantly from those obtained assuming that the coating is a monolayer film, which points out that a reconsideration of the use of the ISO 14577-4 standard for multilayer coatings is required.

The analysis of the elastic stresses developed in the coated system under spherical indentation loading at room temperature indicates that for a maximum contact pressure in the range of $540 \mathrm{MPa}$, no failure of the coated system is expected.

\section{Acknowledgments}

The authors would like to acknowledge to S. K. Field and K. Cooke from MIBA (Teer Coatings, Worcestershire, United Kingdom) for the provision of the coated samples and many fruitful discussions. The assistance of Dr. Y. Perez is also acknowledged for conducting part of the experimental work. The authors also gratefully acknowledge for their support: the European Community, the Ministry of Higher Education and Research, and the National Center for Scientific Research, the International Campus on Safety and Intermodality in Transportation (CISIT), the French Nord-Pas-de-Calais Region and the Regional Delegation for Research and Technology. Professor Puchi-Cabrera gratefully acknowledges the financial support of the program Campus France and the infrastructure provided by the Laboratory LAMIH at the University of Valenciennes, France.

\section{References}

[1] Ghiotti A, Bruschi S. Tribological behaviour of DLC coatings for sheet metal forming tools. Wear 2011;271:2454-8.

[2] Wank A, Reisel G, Wielage B. Behavior of DLC coatings in lubricant free cold massive forming of aluminium. Surf Coat Technol 2006;201:822-7.

[3] Bay N, Azushima A, Groche P, Ishibashi I, Merklein M, Morishita M, Nakamura T, Schmid S, Yoshida M. Environmentally benign tribo-systems for metal forming. CIRP Ann-Manuf Technol 2010;59:760-80.

[4] Bhowmick S, Alpas AT. The performance of hydrogenated and nonhydrogenated diamond-like carbon tool coatings during the dry drilling of 319 Al. Int J Mach Tools Manuf 2008;48:802-14.

[5] Bull SJ. Tribology of carbon coatings: DLC, diamond and beyond. Diamond Relat Mater 1995;4:827-36.

[6] Neuville S, Matthews A. Review-a perspective on the optimisation of hard carbon and related coatings for engineering applications. Thin Solid Films 2007;515:6619-53.

[7] Bewilogua K, Hofmann D. History of diamond-like carbon films-from first experiments to worldwide applications. Surf Coat Technol 2014;242:214-25.

[8] Murakawa M, Takeuchi S. Evaluation of tribological properties of DLC films used in sheet forming of aluminum sheet. Surf Coat Technol 2003;163164:561-5.

[9] Konca E, Cheng Y-T, Weiner AM, Dasch JM, Alpas AT. Elevated temperature tribological behavior of non-hydrogenated diamond-like carbon coatings against 319 aluminum alloy. Wear 2005;259:795.

[10] Ni W, Cheng Y-T, Weiner AM, Perry TA. Tribological behavior of diamond-likecarbon (DLC) hydrogenated and non-hydrogenated coatings against aluminum alloys at elevated temperatures. Surf Coat Technol 2006;201:3229-34.

[11] Abou Gharam A, Lukitsch MJ, Balogh MP, Alpas AT. High temperature tribological behaviour of carbon based (B4C and DLC) coatings in sliding contact with aluminum. Thin Solid Films 2010:1611-7. 
[12] Zou CW, Wang HJ, Feng L, Xue SW. Effects of $\mathrm{Cr}$ concentrations on the microstructure, hardness, and temperature-dependent tribological properties of Cr-DLC coatings. Applied Surface Science 2013;286:137-41.

[13] Zhang S, Bui XL, Li X. Thermal stability and oxidation properties of magnetron sputtered diamond-like carbon and its nanocomposite coatings. Diamond Relat Mater 2006;15:972-6.

[14] Hofmann D, Kunkel S, Bewilogua K, Wittorf R. From DLC to Si-DLC based layer systems with optimized properties for tribological applications. Surf Coat Technol 2013;215:357-63.

[15] Jantschner O, Field SK, Music D, Terziyska VL, Schneider JM, Munnik F, Zorn K, Mitterer C. Sputtered Si-containing low-friction carbon coatings for elevated temperatures. Tribol Int 2014;77:15-23.

[16] Draxler M, Field SK, Preinfalk K, Carbon based coating. Patent US 2014/ 0329070A1 2014

[17] Bohme O, Cebollada A, Yang S, Teer DG, Albella JM, Roman E. Substrate-layer interface of amorphous-carbon hard coatings. J Appl Phys 2000;88(4):1861-6.

[18] Bull SJ. Interface engineering and graded films: Structure and characterization. J Vac Sci Technol 2001;19:1404-14.

[19] Puchi-Cabrera ES, Staia MH, Iost A. Modeling the composite hardness of multilayer coated systems. Thin Solid Films 2015·578:53-62.

[20] Oliver WC, Pharr GM. Measurement of hardness and elastic modulus by instrumented indentation: Advances in understanding and refinements to methodology. J Mater Res 2004;19:3-20.

[21] Li L, Zhou J, Duszczyk J. A 3D FEM simulation study on the isothermal extrusion of a 7075 aluminium billet with a predetermined non-linear temperature distribution, Modelling Simul. Mater Sci Eng 2003;11:401-16.

[22] Chanda T, Zhou J, Duszczyk J. FEM analysis of aluminium extrusion through square and round dies. Mater Des 2000;21:323-35.

[23] Staia MH, Puchi Cabrera ES, Iost A, Zairi A, Belayer S, Van Gorp A. Tribological response of AA 2024-T3 aluminium alloy coated with a DLC duplex coating. Tribol Int 2015;85:74-87.

[24] Chen J, Bull SJ. On the relationship between plastic zone radius and maximum depth during nanoindentation. Surf Coat Technol 2006;201:4289-93.

[25] Puchi-Cabrera ES. A new model for the computation of the composite hardness of coated systems. Surf Coat Technol 2002;160:177-86.

[26] Puchi-Cabrera ES. Computation of composite hardness of coated systems. Surf Eng 2004;20(5):332-44.

[27] Jönsson B, Hogmark S. Hardness measurements of thin films. Thin Solid Films 1984; 114:257-69.

[28] Korsunsky AM, McGurk MR, Bull SJ, Page TF. On the hardness of coated systems. Surf Coat Technol 1998:99:171-83.

[29] Norme Européenne NF EN 14577-4, Matériaux Métalliques: Essai de pénétration instrumenté pour la détermination de la dureté et des paramètres de matériaux. Partie 4: Méthode d’essai pour les revêtements métalliques et non métalliques, 2007.

[30] Doerner MF, Nix WD. A method for interpreting the data from depth-sensing indentation instruments. J Mater Res 1986;1:601-9.

[31] Menčík J, Munz D, Quandt E, Weppelmann ER, Swain MV. Determination of elastic modulus of thin layers using nanoindentation. J Mater Res 1997; $12: 2475-84$

[32] Puchi-Cabrera ES, Staia MH, Iost A. A description of the composite elastic modulus of multilayer coated systems. Thin Solid Films 2015. http://dx.doi. org/10.1016/i.tsf.2015.02.078.

[33] Jarratt M, Stallard J, Renevier NM, Teer DG. An improved diamond-like carbon coating with exceptional wear properties. Diamond Relat Mate 2003; $12: 1003-7$.

[34] Zhang F, Krishnaswamy S, Fei D, Rebinsky DA, Feng B. Ultrasonic characterization of mechanical properties of $\mathrm{Cr}$ - and $\mathrm{W}$-doped diamond-like carbon hard coatings. Thin Solid Films 2006;503:250-8.

[35] Johnson KL. Contact Mechanics. first editionCambridge University Press; 1985

[36] Jacobs R, Meneve J, Dyson G, Teer DG, Jennett NM, Harris P, von Stebut J Comte C, Feuchter P, Cavaleiro A, Ronkainen H, Holmberg K, Beck U, Reiners G, Ingelbrechti $\mathrm{CD}$. A certified reference material for the scratch test. Surf Coat Technol 2003;174-175:1008-13.

[37] Field SK, Jarratt M, Teer DG. Tribological properties of graphite-like and diamond-like carbon coatings. Tribol Int 2004;37:949-56.

[38] Wang L, Bai L, Lu Z, Zhang G, Wu Z. Influence of load on the tribological behavior of a-C films: experiment and calculation coupling. Tribol Lett 2013;52:469-75.

[39] Ronkainen $H$, Holmberg K. Environmental and thermal effects on the tribological performance of DLC coatings. In: Donnet C, Erdemir A, editors. Tribology of diamond-like carbon films: fundamentals and applications. Springer; 2008. p. 155-200.

[40] Andersson BJ, Erck RA, Erdemir A. Friction of diamond-like carbon films in different atmospheres. Wear 2003;254:1070-5.

[41] Fountzoulas CG, Demaree JD, Sengupta LC, Hirvonen JK. Thermal annealing behavior of Si-DLC IBAD coatings. MRS Proc 1996;438:587. http://dx.doi.org/ 10.1557/PROC-438-587.

[42] Jahanmir S (Ed.), Friction and Wear of Ceramics, Materials Engineering Series 1994 Marcel Dekker, INC., New York 53.

[43] Choi J, Nakao S, Miyagawa S, Ikeyama M, Miyagawa Y. The effects of S: incorporation on the thermal and tribological properties of DLC films deposited by PBII\&D with bipolar pulses. Surf Coat Technol 2007;201:8357-61. 